SANDIA REPORT SAND81-0847 • Unlimited Release • UC-32

Printed April 1984

\title{
Mathematical and Numerical Modeling Considerations for Radionuclide Ion Migration in Porous Media
}

\author{
A. H. Treadway \\ Prepared by \\ Sandia National Laboratories \\ Albuquerque, New Mexico 87185 and Livermore, California 94550 \\ for the United States Department of Energy \\ under Contract DE-AC04-76DP00789
}


Issued by Sandia National Laboratories, operated for the United States Department of Energy by Sandia Corporation.

NOTICE: This report was prepared as an account of work sponsored by an agency of the United States Government. Neither the United States Govern ment nor any agency thereof, nor any of their employees, nor any of their contractors, subcontractors, or their employees, makes any warranty, express or implied, or assumes any legal liability or responsibility for the press or implied, or assumes any legal liability or responsibility for the
accuracy, completeness, or usefulness of any information, apparatus, product, or process disclosed, or represents that its use would not infringe privately owned rights. Reference herein to any specific commercial product, process, or service by trade name, trademark, manufacturer, or otherwise, does not necessarily constitute or imply its endorsement, recommendation or favoring by the United States Government, any agency thereof or any of or favoring by the United States Government, any agency thereof or any of
their contractors or subcontractors. The views and opinions expressed herein do not necessarily state or reflect those of the United States Government, any agency thereof or any of their contractors or subcontractors.

Printed in the United States of America Available from

National Technical Information Service

U.S. Department of Commerce

5285 Port Royal Road

Springfield, VA 22161

NTIS price codes

Printed copy: A04

Microfiche copy: A01 
SAND8 1-0847

Unlimited Release

Printed April 1984
Distribution

Category UC- 32

\title{
MATHEMATICAL AND NUMERICAL MODELING CONSIDERATIONS FOR RADIONUCLIDE ION MIGRATION IN POROUS MEDIA
}

\author{
A. H. Treadway \\ Division 2646 \\ Sandia National Laboratories \\ Albuguerque. NM 87185
}

\begin{abstract}
The equations governing radionuclide transport in sorbing. porous media are presented using phenomenological coefficients. Both equilibrium controlled and simple rate controlled chemistry are summarized. several simplified models are discussed. Finally. various numerical problems are considered.
\end{abstract}


Intentionally Left Blank 


\section{CONTENTS}

Page

1. Introduction

2. Balance Equations

3. Chemistry

21

4. Experimental Coetticients

24

5. Simplitied Models

24

6. Numerical Considerations

39

7. Conclusions

41

Appendix

43

Reterences

Figures 
Intentionally Left Blank 
Mathematical and Numerical Modeling Considerations for Radionuclide lon Migration in Porous Media

\section{Introduction}

Several types of depositories have been proposed for the storage of radioactive waste. Among these depositories are the sediments of the seabed, salt formations, and granite. Since it must be presumed that radionuclides will migrate from the storage sites to the outside environment, a mathematical model is needed in order to determine a bound on the flux of these radionuclides at the various interfaces of the depositories of interest. Due to the complexity of the equations that describe radionuclide migration in sorbing porous media, numerical solutions, in all likelihood. will be required.

The purpose of this report is fourfold. First, it is to collect, in one place, the equations of a fairly general mathematical model which can be used in analyzing radionuclide migration in sorbing porous media. Second, it is to review the coefficients that must be determined experimentally for a model. Third. it is to present some simple models which can be used to get "bounds" on the fluxes of interest. Fourth, the report considers the possible effects that the model could have on numerical techniques used in solving the governing partial 
differential equations (PDEs). A unpublished report. Treadway (1981). examines numerical technigues for radionuclide problems in detail.

In section 2, the balance equations will be presented without any attempt at derivation. Section 3 will describe various chemical models along with an experimental curve for a concentration-dependent radionuclide distribution coefficient. In section 4, the coefficients requiring experimental determination will be sumarized. Some simplified models along with their solutions will be discussed in section 5. In section 6, possible numerical difficulties will be examined. Finally, a few conclusions will be drawn concerning simulating radionuclide ion migration, and concerning upper bounds to the concentration fluxes at boundaries.

This report is the result of work begun in 1976 on the seabed Disposal Project. The principle aims of that work were (1) to review the currently available models, (2) to investigate the effects of the porous structure on radionuclide migration. (3) to ascertain the possible consequences of assuming non-trace chemistry in the models, and finally (4) to develop a numerical code which could be used over a wide range of concentrations. going from the simplest trace, to fairly high concentrations. These latter concentrations can occur in certain experiments associated with the project. 


\section{Balance Equations}

In this section. we have endeavored to collect together many of the models available in the literature. Many terms in the equations have been kept for the sake of completeness, although for most applications, they are quite small. Furthermore, no attempt has been made to provide a derivation of the equations. It should be pointed out that the equations in the report were obtained for the seabed Disposal Project. However, the equations (with some modifications) should be useful for other radionuclide migration studies.

There are basically two philosophies in obtaining the governing equations for migration in porous media. The first is to assume that the equations of fluid dynamics hold microscopically in the pore spaces and then to average over some representative volume of the porous media. The averaging step attempts to take into account the curvature and size of the pore channels assuming. for instance, that the flow in the channels can be approximated by Poiseuille flow in a tube. The net result is that the mass and energy equations are basically the same with certain velocity dependent "dispersion" terms "added" and Darcy's law replacing the momentum equation. Many cross-coupling terms seem to disappear in this approach. The interested reader is referred to Bear (1972) for a discussion of the above approach. The second approach (see for example. Groenevelt et al. (1969). de Groot (1951). Katchalsky and Curran (1965), and Taylor and 
Cary (1964)) is to average and then use the theory of irreversible thermodynamics to obtain the macroscopic equations. This approach is more general than the first and cross-coupling arises naturally. It is the latter approach which will be adopted in this report.

Our model will be concerned with the time atter the radionuclide waste cannister has been successtully implanted in the porous seabed sediments. The radionuclides are presumed to "escape" trom the cannister by some mechanism and begin to migrate through the sediments. Atter a finite time the radionuclide ions will reach the seabed-sea interface and conseguentiy migrate into the biosphere.

In developing the mathematical model to describe the migration of the radionuclides in the seabed sediments and to thus calculate the flux at the seabed-sea interface, we have assumed that (1) the temperature of the tluid and porous media are the same, (2) the porous media is saturated, and (3) the porous media is rigid. The second assumption essentially states that there is only liguid present in the pore space. implying that the cannister is not hot enough to dry the surrounding medium. The third assumption presumes that the cannister remains intact tor a sufficient time atter burial for the media to reach a timeindependent equilibrium state. The last two assumptions can be removed (see Freeze (1971) for (2) and cooper (1966) for (3)). 
However, more experimental data will be needed for the various constitutive relations.

\subsection{Mass Balance}

For each species present, we have

$$
\begin{aligned}
\frac{\partial}{\partial t}\left(\Theta C_{i}+\rho_{B} \bar{C}_{i}\right) & =-\nabla \cdot \eta_{i}-\lambda_{i}\left(\theta C_{i}+\rho_{B} \bar{C}_{i}\right) \\
& +\lambda_{i-1}\left(\theta C_{i-1}+\rho_{B} \bar{C}_{i-1}\right)+s_{i}
\end{aligned}
$$

where

$\Theta$

$\rho_{\mathrm{B}}$

$\mathrm{C}_{\mathrm{i}}$

$\mathrm{C}_{\text {i }}$

$\eta_{i}=\theta c_{i} v_{i}$

$v_{i}$

$\lambda_{i} \cdot \lambda_{i-1}$

$\mathbf{S}_{\mathbf{i}}$ volumetric water content of medium. $\mathrm{cm}^{3}$ of solution per $\mathrm{cm}^{3}$ bulk bulk density of the medium, $\mathrm{gm} / \mathrm{cm}^{3}$ of soil

amount of ionic species $i$ in solution phase. $\mathrm{gm} / \mathrm{cm}^{3}$ of liquid amount of ionic species $i$ sorbed by solid phase, gm/gm of soil

flux of component $i . \mathrm{gm} / \mathrm{cm}^{2}$ bulk/sec velocity of component i. $\mathrm{cm} / \mathrm{sec}$ decay constants source or production term, $\mathrm{gm} / \mathrm{cm}^{3}$ bulk/sec 
It must be noted that the term $\rho_{B} \lambda_{i-1} \bar{c}_{i-1}$ appearing in (2.1) is to be interpreted as the amount of species $i$ present due the decay of the $i-1$ species. See section 3.1 for more detail.

Introducing into Equation (2.1), the flux of component i relative to the mean pore water velocity. $j_{v} / \Theta$, namely

$j_{i}^{R}=\frac{\eta_{i}}{c_{i}}-j_{v}$

gives

$$
\begin{aligned}
\frac{\partial}{\partial t}\left(\Theta C_{i}+\rho_{B} \bar{C}_{i}\right)+V \cdot c_{i} j_{v} & =-\nabla \cdot c_{i} j_{i}^{R} \\
& -\lambda_{i}\left(\theta c_{i}+\rho_{B} \bar{c}_{i}\right) \\
& +\lambda_{i-1}\left(\theta c_{i-1}+\rho_{B} \bar{c}_{i-1}\right)+s_{i}
\end{aligned}
$$

where the Darcy velocity (volume $t$ lux) $j_{v}$ is detined as

$j_{v}=\sum_{\ell} \Phi_{\ell} v_{\ell}$ (liquid components)

expressed in $\mathrm{cm}^{3}$ liquid $/ \mathrm{cm}^{2}$ bulk/sec and the $\Phi_{\ell}$ are the macroscopic volume fractions such that

$$
\sum_{\ell} \Phi_{\ell}=\Theta
$$

Under saturated conditions, $\Theta$ is equal to the porosity, $\varepsilon$. 


\subsection{Energy Balance}

Following Taylor and Cary (1964). Groenevelt and Bolt (1969), and Mercer and Faust (1979), we have

$\frac{\partial}{\partial t}\left(\theta \rho_{f} U+(1-\theta) \rho_{s} U_{s}\right)=-\nabla \cdot J_{q}+\sum_{i} \eta_{i} \cdot \bar{g}_{i}$

where the acceleration of the center-of-mass, velocitysquared terms, pressure work term, and viscous dissipation have been neglected. In addition, the soil matrix is assumed rigid. In the above

$\begin{array}{ll}\rho_{f} & \text { total liquid density } \\ \rho_{S} & \text { density of the soil matrix } \\ U_{S} & \text { internal energy of soil matrix } \\ U & \text { internal energy of the liquid mixture } \\ J_{q} & \text { heat flux } \\ \bar{g}_{i} & \text { external forces on component } i\end{array}$

\subsection{Fluxes}

In keeping with our approach of using the linear phenomenological equations of irreversible thermodynamics, we will assume that the system of interest is not too distant from equilibrium and that the processes are sufficiently slow. For the seabed Disposal Project, these assumptions are quite reasonable since the cannister temperature is 
expected to be on the order of a few hundred ${ }^{\circ} \mathrm{C}$ : thus, the velocity, temperature, and pressure fields around the cannister should be smal1. Schimmel et al. (1977).

The phenomenological equations can be written as

$$
J_{i}=\sum_{k} L_{i k} \bar{x}_{k}
$$

where $J_{i}$ are the fluxes. $L_{i k}$ the phenomenological coefficients, and $\underline{\underline{x}}_{k}$ are the conjugated forces. In Equation (2.6). the $\mathrm{L}_{\mathrm{ik}}$ may depend on the concentrations. temperature. pressure. charge. etc.. but cannot be functions of either the fluxes or the torces.

There is currently work being done on nonlinear transport in which higher order terms. (powers and products of the forces) are kept. (see Rastogi, singh, srevastava (1969).) However. the nonlinear theory is very incomplete and as a result we will consider only the linear theory in this report.

If the forces and fluxes are chosen so that the entropy production, $\sigma$, (or To, where $T$ is the temperature) is given by

$$
\sigma=\sum \mathrm{J}_{\mathrm{i}} \overline{\mathrm{x}}_{\mathrm{i}}
$$


then

$L_{i k}=L_{k i}$

Furthermore, since $\sigma>0$, then

$L_{i i}>0$

and

$L_{i j} L_{i j} \geq L_{i j}^{2}$

Before continuing. it should be noted that for the seabed Project there are ten seawater ions present. Millero (1974). and that the seabed is clay-like in nature. Consequently, we are dealing with an electrolyte, and the pores will have a charge. As a result. "electrokinetic eftects" must be considered in the model. For the remainder of the discussion we will assume electroneutrality, that is.

$\sum z_{i} F\left(\Theta C_{i}+\rho_{B} \bar{C}_{i}\right)+z=0$

where $Z_{i}$ is the valence of the $i t h$ ionic species. $F$ is Faraday's constant, and $Z$ is the pore charge. In addition. since there are no electrodes completing a circuit, we have no current tow, viz.

$$
I=0=\sum \mathrm{Z}_{i} \mathrm{FJ}_{i}
$$


It can be shown (Groenevelt and Bolt (1969)) that

$$
\begin{aligned}
\mathrm{T} \sigma=\mathrm{J}_{\mathrm{q}}^{\prime} & \bullet \nabla(-\ln \mathrm{T})+\mathrm{J}^{\mathrm{V}} \cdot(\nabla(-\mathrm{P})-\rho \overline{\mathrm{g}}) \\
& +\sum_{i}^{\mathrm{n}-1} \mathrm{~J}_{i}^{\mathrm{D}} \cdot\left[\rho_{i} \nabla\left(-\mu_{i}^{\mathrm{C}}\right)-\rho_{i}\left(1-\overline{\mathrm{V}}_{i} \rho\right) \overline{\mathrm{g}}\right] \\
& +\mathrm{I} \cdot V(-\psi)+\mathrm{J}_{\tilde{A}}^{C H_{\tilde{A}}}
\end{aligned}
$$

where

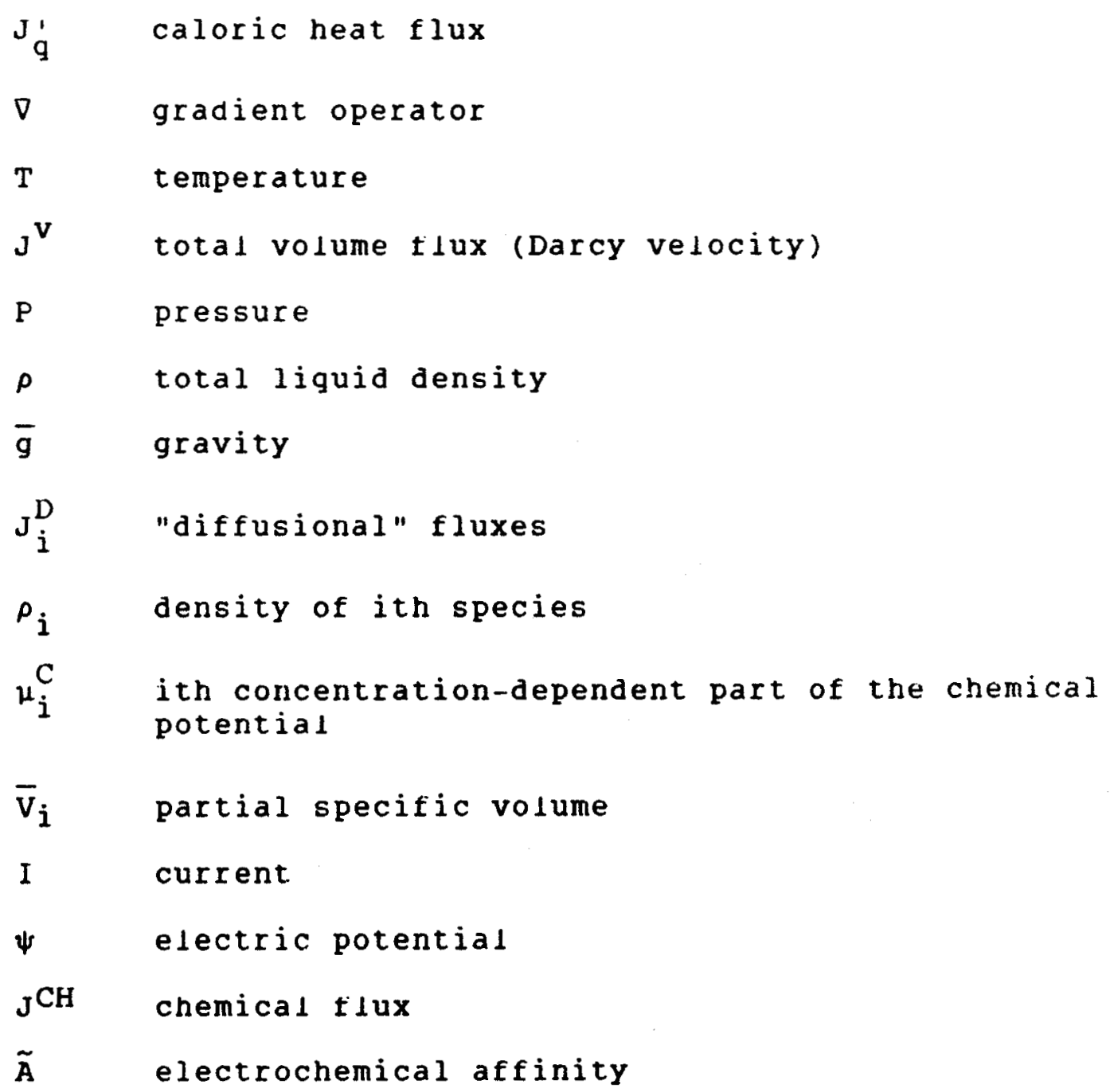


with

$$
J_{v} \equiv J_{w} \bar{v}_{w}+\sum_{i} J_{i} \bar{v}_{i} \quad, \quad i \neq w
$$

$$
J_{i}^{D} \equiv\left(\frac{J_{i}}{\rho_{i}}-\frac{J_{w}}{\rho_{w}}\right), \quad i \neq w
$$

If chemical reactions can be neglected and since the term $\rho_{i}\left(1-\bar{V}_{j} \rho\right) g$ is negligible tor gravity, then the tluxes are $J=\left\{J_{q}^{\prime}, J^{V}, J_{i}^{D}, I\right\}$ and the conjugated torces are

$\underline{\bar{x}}=\left\{-\nabla \perp n T,-(\nabla P+\rho g),-\rho_{i} \nabla_{i}^{C} \cdot-\nabla \psi\right\}$.

since the balance equations contain fluxes difterent from the above, it wi $\perp \perp$ be necessary to express them in terms of the $t \perp u x$ set $J$ above.

Now the relation between $\left\{j^{v}, j_{i}^{R}\right\}$ in Equation (2.3) and $\left\{J^{v}, J_{i}^{D}\right\}$ is, that for $c_{i}=\rho_{i}$,

$$
j_{v}=J_{v}
$$

and

$j_{i}^{R}=\frac{\theta J_{i}^{D}-\sum \Phi_{k} J_{k}^{D}}{\Theta}$. 
where

$\Phi_{i}=\rho_{i} \bar{V}_{i} \Theta$

In addition, since

$J_{q}^{\prime}=J_{q}-\sum \bar{n}_{i} J_{i}$

where $\bar{h}_{i}$ is the partial specitic enthalpy, we have

$$
J_{q}=J_{q}^{\prime}+h j^{v}+\sum \rho_{i} \bar{h}_{i} j_{i}^{R}
$$

with

$n=\sum \rho_{i} \bar{h}_{i}$

The last term of Equation (2.18) is generally much smaller than the first two.

From the above relations. once the phenomenological coetficients have been determined, the $t$ luxes appearing in Equations (2.3) and (2.5) are known.

\subsection{Coupling}

Using the fluxes and conjugated forces found in the last section. Equation (2.6) may be written as 


$$
\begin{aligned}
& \mathrm{J}_{\mathrm{q}}^{\prime}=-\mathrm{L}_{\mathrm{q} 1} \nabla \perp \mathrm{nT}-\mathrm{L}_{\mathrm{q} 2}(\nabla \mathrm{P}+\rho \overline{\mathrm{g}})-\mathrm{L}_{\mathrm{q} 3} \nabla \psi-\sum_{\mathrm{K}=1} \mathrm{~L}_{\mathrm{q}, \mathrm{K}+3} \rho_{\mathrm{K}} \nabla_{\mu_{\mathrm{K}}}^{\mathrm{C}} \\
& J^{v}=-L_{v l} \nabla 1 n T-L_{v 2}(\nabla P+\rho \bar{g})-L_{v 3} \nabla \psi-\sum_{k=1} L_{v} k+3^{\rho}{ }_{k} \nabla \mu_{k}^{C} \\
& I=-L_{I I} \nabla \ln T-L_{12}(\nabla P+\rho \bar{g})-L_{I 3} \nabla \psi-\sum_{K=1} L_{1, k+3} \rho_{K} \nabla \mu_{K}^{C} \\
& J_{i}^{D}=-L_{i 1}^{D} \nabla 1 n T-L_{i 2}^{D}(\nabla P+\rho \bar{g})-L_{i 3}^{D} \nabla \Psi-\sum_{k=1} L_{i, k+3}^{D} \rho_{k} \nabla \mu_{k}^{C}
\end{aligned}
$$

Now

$$
\nabla \mu_{k}^{C}=\sum_{j}^{N-1} \frac{\partial \mu_{k}^{C}}{\partial C_{j}} \nabla C_{j}
$$

where the $C_{i}$ 's are the concentration tractions and

$$
\sum c_{i}=1 \text {. }
$$

with $\mathbf{N}$ being the number of species.

Consequent1y.

$\sum_{k} L_{i, k+3}^{D} \rho_{k} \quad \nabla \mu_{k}^{C}=\sum_{j}\left(\sum_{k} L_{i, k+3}^{D} \rho_{k} \frac{\partial \mu_{k}^{C}}{\partial C_{j}}\right) \nabla C_{j}$.

Detining

$$
D_{i j}=\sum_{k} L_{i, k+3}^{D} \rho_{k} \frac{\partial \mu_{k}^{C}}{\partial C_{j}}
$$


then $\underset{\sim}{D}$ is recognized as the "hydrodynamical dispersion tensor" and must be considered a "lumped" coefficient, as are the other coefficients which include effects of macroscopization, Elrick et al.(1975).

In Equation (2.20) above. for the remaining straight coetticients, we have

$\frac{L_{\mathrm{gl}}}{\mathrm{T}}$ the system thermal conductivity.

$L_{\text {V2 }}$ the hydraulic conductivity.

L 3 the system electrical conductivity.

Furthermore, since $1=0, \nabla \psi$ can be expressed in terms of the remaining forces. As a result, L., can be set to zero in $\mathrm{J}_{\mathrm{q}} \cdot \mathrm{J}^{\mathrm{V}} \cdot \mathrm{J}_{\dot{i}}^{\mathrm{D}}$ which gives a reduced set of coetticients to be found. In addition. the Dufour effect and soret effect, $i . e .$. the $\sum_{k} L_{g, k+3} \rho_{k} \nabla_{\mu_{k}}^{C}$ and $L_{i l}^{D}$ VInT terms. respectively, are usually small unless there are large gradients.

summarizing.

$J_{\dot{q}}^{\prime}=-L_{q 1}^{\prime} V \ln T-L_{q 2}^{\prime}(\nabla P+\rho \bar{g})$

$J^{V}=-L_{v 1}^{\prime} V I n T-L_{v 2}^{\prime}(\nabla P+\rho \bar{g})+\sum L_{v j}^{\prime} \nabla C_{j}$

$\mathrm{J}_{i}^{\mathrm{D}}=-\mathrm{L}_{i 2}^{D^{\prime}}(\nabla \mathrm{P}+\rho \overline{\mathrm{g}})+\sum_{j} D_{i j} V \bar{C}_{j}$ 
where, indicates the tact that $I=0$. Without turther knowledge of the above coetticients. which are not available tor the seabed Project, the cross-coupling terms must be kept. Bolt and Groenevelt (1969) have shown that the cross-coupling can account for the non-Darcian behavior observed in many soil/water systems.

\subsection{Chemistry}

In order to solve Equation (2.1), we need $\frac{\partial \bar{C}_{i}}{\partial t}$. There are two possible control modes for the chemistry. One is equilibrium controlled and the other is rate controlled.

\subsection{Equilibrium Controlled}

In equilibrium-controlled chemistry. relationships of the torm

$\mathrm{I}_{i}(\overline{\underline{C}}, \underline{C})=0 \quad i=1, \ldots, N$

connect the amount sorbed by the solid media and the amount of the species in solution. Some examples are

$$
\begin{aligned}
& \bar{c}_{i}=\frac{\alpha_{i} c_{i}}{\sum \alpha_{j} c_{j}} \\
& k_{i}^{j}=\left(\frac{\bar{c}_{j}}{\bar{c}_{j}}\right)^{\nu}\left(\frac{c_{i}}{\bar{c}_{i}}\right)^{\nu} j
\end{aligned}
$$


$\bar{c}_{i}=K_{d}^{i}(\underline{c}) c_{i}$

(Distribution)

$(3.2 \mathrm{c})$

where $K_{d}^{i}$ is a distribution coefficient and $k_{j}^{j}$ are selectivity coefficients (e.g.. see Helfferich and klein (1970) and Elrick et al. (1975)).

For the Seabed Disposal Project, a "lumped" group distribution coefficient has been determined experimentally. Erickson (1977). It is

$K_{d}(\mathrm{c})=\frac{10^{2}}{1+10^{3} \mathrm{c}}+\frac{2 \times 10^{4}}{1+2 \times 10^{7} \mathrm{c}} \cdot \mathrm{ml} / \mathrm{gm}$

where $c$ is in moles/l and is shown in Figure 1. This $K_{d}$ represents a two mechanism "Langmuir" type isotherm, and is valid for very high concentrations of 0.1 moles/l down to trace concentrations of $10^{-11}$ moles/ $\ell$ and infinitely dilute solutions. We will show some numerical results using this $K_{d}$ later.

To find $\frac{\partial \bar{C}_{i}}{\partial t}$, differentiate (3.1), (3.2). or (3.3) with respect to (wrt) $t$, and then solve for $\frac{\partial \bar{c}_{i}}{\partial t}$ from the resulting equations.

As was mentioned in section 2 , some care is required when using $\bar{C}_{j-1}$ in a chain decay problem. Using the distribution coetticient $(3.2 \mathrm{c})$ we have 
$\bar{c}_{i}=K_{d}^{i}(\underline{C}) C_{i}$

In Equation (2.1) we put

$\bar{c}_{i-1}=k_{d}^{i}(\underline{C}) c_{i-1}$

since $\lambda_{i-1} C_{i-1}$ represents the amount of species $i-1$ that has decayed to species $i$.

\subsection{Rate Controlled}

It the chemistry is not in equilibrium, then $\frac{\partial \bar{C}_{i}}{\partial t}$ must be determined trom a set of n-coupled rate equations. For example. Bradley and sweet (1975).

$\frac{\partial \bar{C}_{i}}{\partial t}=\sum_{k=1}^{N} s_{i k}\left(\bar{c}_{k}^{*}-\bar{c}_{k}\right) \quad i=1, \ldots N$

where

$$
S_{i k} \text { is a stanton number }
$$

and

$$
\bar{c}_{i}^{\star}=t_{i}\left(c_{i}, \ldots, c_{N}\right)
$$

$\bar{C}_{i}^{*}$ is the solid phase concentration in equilibrium with the liquid phase. Equation (3.4) must be considered as an approximation. particularly tor transient systems. 


\subsection{Experimental Coetticients}

As is evident from the previous sections, there are a considerable number of coefficients in the mathematical model. Unfortunately, most of these coefficients must be determined experimentally. In the absence of any cross-coupling, there are models available for the straight phenomenological coefficients. However, because there is no reason to believe that for the seabed Project that "electrokinetic" cross-coupling terms or the other cross-coupling terms are negligible, it would seem best to determine all of the coefficients experimentaly. It should be noted that as the concentration decreases to trace levels, the cross-coupling effects become negligible. It is obvious that the above determination will not be easy. However, to make predictions for waste disposal on highly incomplete information seems unwise.

Gathering the coefficients requiring experimental determination. we find $\theta, \rho_{B}, Z, \mu_{i}^{C}, D_{i j} \cdot L_{q i}^{\prime}, L_{v_{i}}^{\prime} \cdot L_{I i}, L_{i 2}^{D^{\prime}} \cdot K_{d}^{i}$ or $K_{j}^{i}$ It has been assumed that models are available for $\rho_{S} U_{S} \rho_{i} \cdot U$. $\overline{\mathrm{h}}_{\mathrm{i}}, \overline{\mathrm{v}}_{\mathrm{i}} \cdot$

\subsection{Simplified Models}

In order to gain some insight into how the nonlinear chemistry might affect the transport of radionuclides. some drastic simplifications will be made in this section. There are two 
types of problems which are readily amenable to treatment. One is the one-dimensional diftusion equation. and the other is the one-dimensional advection equation.

\subsection{Nontinear Dittusion}

It we assume that there are no thermal eftects, no decay terms, no cross-coupling, no velocity tlux, only one ion present, and one space dimension, we have

$\frac{\partial}{\partial t}\left(C+\frac{\rho_{B}}{\theta} \bar{C}\right)=\frac{\partial}{\partial x} D \frac{\partial C}{\partial x}$

where $\bar{C}$ is given by Equation (3.3). We will take $\frac{\rho_{B}}{\dot{\theta}}=5.4$. and $1.0 \mathrm{gm} / \mathrm{cm}^{3}$. The tirst value of $\frac{\rho_{B}}{\Theta}$ is an average value tor soils while the second is an average value tor sea sediments. For initial conditions

$C(x, 0)=0$

and tor boundary conditions

$c(0, t)=C_{0}($ constant $)$

and

$\lim C(L, t)=0$.

$\mathrm{L} \rightarrow \infty$ 
Letting $\tau=D t$. Equation (5.1) can be written as

$w(C) \frac{\partial C}{\partial \tau}=\frac{\partial^{2} c}{\partial x^{2}}$.

where

$w(C)=\frac{d}{d c}\left(C+5.4 K_{d}(C) C\right)$

and is shown in Figure 2. Note that $w(C)$ can vary by five orders of magnitude.

Because of the form of the initial and boundary conditions. Equation (5.4) can be solved using a similarity transformation. Let

$\eta=\frac{x}{\sqrt{\tau}}$

then

$\frac{\partial}{\partial x}=\frac{1}{\sqrt{\tau}} \frac{d}{d \eta}$.

and

$\frac{\partial}{\partial \tau}=-\frac{x}{2 \tau^{3 / 2}} \frac{d}{d \eta}$

Consequently. Equation (5.4) becomes

$\frac{d^{2} \tilde{c}}{d \eta^{2}}+\frac{\eta \pi}{2} \tilde{w}(c) \frac{d \tilde{c}}{d \eta}=0$ 
where

$\tilde{c}=c / c_{0}$

$\tilde{w}(C)=w(C) / w_{0}$

$w_{0}=w\left(C_{0}\right)$

with BCs

$\tilde{C}(0)=1$

$\lim \tilde{C}(L)=0$.

$L \rightarrow \infty$

Note that in using $\tilde{w}(C)$ in Equation (5.9) $\tau$ has been rescaled such that

$\tau=\mathrm{Dt} / \mathrm{w}_{0}$.

Equation (5.9) subject to conditions (5.10) was solved numerically using a forward-backward shooting technique breifly described below. A more detailed explanation is given in the Appendix.

since we do not know how to handle the second condition in (5.10) numerica11y, we approximate it by

$\tilde{C}(L)=10^{-8}$ 
where $L$ is "sufficiently large". In the forward shooting process $\tilde{C}^{\prime}(0)$ is adjusted until the above condition is satisfied. See Figure $3 a$ for a sketch of the resulting solution. Unfortunately (5.11) is not the correct condition since for $C<10^{-11}$ the solution to Equation (5.9) is

$\tilde{c}(n)=\frac{\tilde{c}_{\star} \operatorname{erfc}\left(\frac{n \sqrt{w_{\star}}}{2}\right)}{\operatorname{erfc}\left(\frac{n \star \sqrt{w_{\star}}}{2}\right)}$

(see the Appendix)

where

$\tilde{c}_{\star}=10^{-11} / C_{0}$

$\mathbf{w}_{\star}=\tilde{\mathbf{w}}\left(10^{-11}\right)$

and $\eta_{\star}$ is unknown. To find $\eta_{\star}$ we differentiate (5.12) wrt $\eta$ to obtain an expression for $\tilde{C}^{\prime}\left(\eta_{\star}\right)$ which along with $\tilde{C}\left(\eta_{\star}\right)$ is used to integrate Equation (5.9) backwards. $\eta_{\star}$ is adjusted until the first condition in (5.10) is met. As a first approximation to $\eta_{*}$, we use the value in Figure $3 a$ where the steep portion of the $\log \tilde{\mathrm{C}}$ vs $\eta$ curve and the flat portion meet. The latter is a result of the $\tilde{C}(L)$ condition used in the forward shooting process. The results 
presented below were calculated using a pure relative error tolerance of $10^{-6}$ in the numerical ordinary differential equation integrators used in the above solution technique.

Equation (5.9) was solved for values of $C_{0}$ of $10^{-1}$. $10^{-3}$, and $10^{-5}$. The results are shown in Figures $3 \mathrm{~b}$. 3c. and $3 d$. respectively. In Figure 3 , the * represents the value of $n$ where the numerical solution ends and the analytical solution begins. The solutions are very similar to the solutions of singular diffusion problems. Crank (1956). Furthermore, it was necessary to use a stiff integrator in the forward process. Both of the above features will present difficulties in trying to numerically solve the associated PDEs. In Figure $3 e$, the previous three curves are plotted using the scaling of $n$ associated with $C_{0}=10^{-1}$. In addition the solution for $w(C) \equiv 1$ is shown for comparison. This latter solution would be the result if chemistry is ignored. $\tilde{c}$ would be equal to $10^{-11}$ at $\eta \approx 9.6$ for this solution.

In Table I, we have provided the values of $\eta_{\star}$ and the associated $\tilde{C}^{\prime}\left(\eta_{\star}\right)$ found from the solution process for the three values of $C_{0}$ considered. The numbers in the table can be used to integrate Equation (5.9) backwards from $\eta_{\star}$ to provide accurate numerical solutions. Forward integration of the equation tends to be less accurate. For values of $\eta>\eta_{*}(5.12)$ is used. 


$\begin{array}{ccc}\mathrm{C}_{0} & \eta_{\star} & \tilde{\mathrm{C}}^{\prime}\left(\eta_{\star}\right) \\ 10^{-1} & .65272219 & -1.0477731 \mathrm{E}-8 \\ 10^{-3} & 2.0026297 & -2.8335045 \mathrm{E}-7 \\ 10^{-5} & 1.3440714 & -9.7427641 \mathrm{E}-6\end{array}$

In order to determine what etfect soil density mignt have on the solutions, the $C_{0}=10^{-1}$ case was resolved using $\frac{P_{B}}{\theta}=1$. The results for the two values are shown in Figure $3 t$. There is considerably less retardation with $\frac{\rho_{\mathrm{B}}}{\Theta}=1$.

As was mentioned in the Introduction, we are interested in the flux at the seabed-sea intertace. This 1 lux is given by

$F=-\left.D \frac{\partial C}{\partial x}\right|_{x=L}=-\left.\frac{C_{0}}{\sqrt{\frac{D t}{w_{0}}}} \frac{d \tilde{C}}{d \eta}\right|_{\eta_{L}}$.

where

$n_{L}=\frac{L}{\sqrt{\frac{D t}{w_{0}}}}$

Increasing the complexity of the model a little. let us assume that the ion not only dittuses through the liquid. but also on the solid particles. In the similarity variable, the equation is 


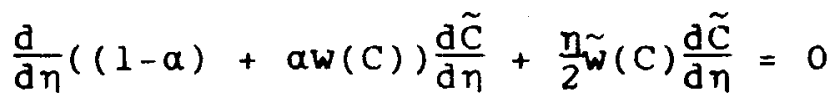

where $a$ is a parameter. A similar numerical technique to that previously described is used to solve the above equation. In Figure 4, we have shown the numerical solution of (5.14) for $\alpha=.01$ and $c_{0}=.1$. For comparison, the solution with $a=0$ (Figure $3 b$ ) is also shown. It should be noted that there is considerable difterence between the solutions. This difference would tend to indicate that solid diffusion might have to be taken into account when developing various bounds.

\subsection{Nonlinear Advection}

Let us assume that we have a constant flow rate. $q$, no "diffusion". and that we adopt the other assumptions of the preceding section. Hence

$\frac{\partial}{\partial \tau}\left(\tilde{C}+5.4 K_{d}(C) \tilde{C}\right)+\frac{\partial \tilde{C}}{\partial x}=0$

where $\tau=q t$.

Equation (5.15) is hyperbolic and as such may be written in characteristic torm. viz.

$$
\begin{aligned}
& \frac{d \tilde{C}}{d \tau}=0 \\
& \frac{d x}{d \tau}=\frac{1}{\tilde{w}(C)} .
\end{aligned}
$$


If the characteristics intersect, then a "shock" will form. It is easy to show, Hilbert and courant (1966), that for shocks we have

$-V_{s}\left[\tilde{C}+5.4 K_{d}(C) \tilde{C}\right]+[\tilde{C}]=0$

where $V_{S}$ is the shock velocity

$[r]=r_{+}-r_{-}$

and $r_{+}$is the value of $r$ ahead of the shock

$r$ is the value of $r$ behind the shock.

In order to see how we might use equations (5.16) and (5.17) to solve Equation (5.15), let

$U=\tilde{C}+5.4 K_{d}(C) \tilde{C}$

Consequently. Equation (5.15) becomes

$\frac{\partial U}{\partial \tau}+\frac{\partial f(U)}{\partial x}=0$

where

$f(U) \equiv \tilde{C}(U)$

Equation (5.20) is the more common form of a hyperbolic PDE . 
Two examples of $f(U)$ are shown in Figure 5. In Figure 5a. $f(U)$ is a convex function, and as a result, any two points on the curve can be connected by a straight line without intersecting the curve. These two points are candidates for the state ahead of the shock and for the state behind the shock, Oleinik (1963). Now in Figure 5b, only certain portions of the $f(U)$ curve can be connected without intersecting the curve, oleinik (1963). For example, it the initial state is $U=0$, then the only states which can be connected to $U=0$ are those values of $U \leq U_{\star}$, where $U_{\star}$ is the solution of

$f^{\prime}\left(U_{\star}\right)=\frac{f\left(U_{\star}\right)}{U_{\star}}$.

$U_{\star}$ in this example is just the point at which a line from the origin is tangent to $f(U)$. (See Figure 5b). In other words, if $U>U_{\star}$. no jump is possible until $U=U_{\star}$.

To see what types of solutions to Equation (5.15) can arise depending on the shape of $t(U)$, consider tirst

$f(U)=\frac{U^{2}}{2}$

with

$U(x, 0)=0 \quad x>0$

$U(0, \tau)=1$. 
Then

$v_{s}=\frac{[f]}{[u]}=\frac{0-1 / 2}{0-1}=\frac{1}{2}$.

The solution is

$U= \begin{cases}1 & \frac{x}{\tau}<\frac{1}{2} \\ 0 & \frac{x}{\tau}>\frac{1}{2}\end{cases}$

that is, a step function traveling with a velocity of one half. The results for this example are shown in a $x-\tau$ diagram in Figure $6 a$.

Now consider

$f(U)=\frac{(U-.16)^{2}}{(U-.16)^{2}+(.8-U)^{2}}$

with the same conditions as before. One easily calculates

$U_{\star}=.6125$

and

$v_{s}=1.3934$

Note that

$v_{s}=\left.\frac{d x}{d \tau}\right|_{u_{*}}$ 
that is, the shock speed and characteristic speed are the same, which implies. that

$\mathbf{U}=\mathbf{U}_{\star}$

along the shock line. If $x / \tau>f^{\prime}\left(U_{\star}\right)$, then $U=0$, and if $x / \tau=f^{\prime}\left(u_{\star}\right)$. then $U=U_{\star}$. However, if $x / \tau<f^{\prime}\left(U_{\star}\right)$, we must solve the equation

$\underline{x}=f^{\prime}(U)$

$0 \leq x \leq \tau f^{\prime}\left(U_{*}\right)$

The solution for this second example is sketched in Figure 7 for arbitrary $\tau$ and also shown in an $x-\tau$ diagram, Figure $6 \mathrm{~b}$.

In order to use the above information, we need a plot of $C(U)$ versus $U$. which is shown in Figure 8. For $C_{0}=.1$ and $\tilde{c}(x, 0)=0$, the solution is

$C(x, \tau)= \begin{cases}.1 & \frac{x}{\tau}<1 / 6.4 \\ 0 & \frac{x}{\tau}>1 / 6.4\end{cases}$

since $(.64, .1)$ and $(0,0)$ are connectable states. As in the diffusion problem. the chemistry does have a retarding effect, but the retardation is considerably smaller. As the initial concentration is reduced, the propagation velocity will also be reduced. It should be noted that 
for this $C(U)$, all points can be connected to the origin due to convexity.

There are some solution techniques available for the multicomponent extension of the advection problem. provided that the chemistry is simple Langmuir (3.2a) or of the type (3.2b) with $v_{i}=v_{j}=1$ and $k_{j}^{i}$ constant. Helfferich and Klein. (1970). (It turns out that these two types of chemistry are the same.) For an interesting application to a radionuclide problem, the interested reader is referred to Nuttall (1976). The report shows what can happen when ion exchange effects are taken into account. Depending on the magnitudes and the orderings of the $k_{j}^{i}$ 's some radionuclides may not be retarded at all or the retardation effect may be signiticantly ditferent than in the case of a single species. One tinds that the radionuclides move in "chromatographic" bands; each species moving with a different ionic velocity.

Unfortunately. indications are that the multicomponent chemistry for the seabed problem will not be of the reguired type. As a result, a multicomponent extension of the method we have outlined will be necessary or one must. solve the governing PDE's numerically. Untortunately. most numerical techniques result in smeared shocks or worse, negative concentrations near the shock, Roache (1976). 


\subsection{Bounds on Concentrations and Fluxes}

One of the assumptions that was made in developing the simplified solutions in the previous two sections was that the decay constant was zero. For radionuclides it. obviously is not. A simple way to account for the decay effect is to multiply the diffusion or advection concentration solutions by $e^{-\lambda \tau}$. The result will be an upper bound for the quantities of interest for the simplitied models.

Now in order to obtain a "global" bound tor the concentration or flux at an interface trom the simplified models, we need a technique which links the advection and diffusion solutions together. It should be noted that it is expected that near the cylinder and for early times. advection will be the dominant transport mechanism while farther from the cylinder, and at later times, the mechanism will be dittusion. See Figure 9.

Assume that a velocity profile, $q(x)$, is known and is such that $g\left(x_{0}\right) \approx 0$. e.g. Hickox (1977). Then the nonlinear advection equation becomes

$\frac{\partial}{\partial \tau}\left(\tilde{C}+R K_{d} \tilde{C}\right)+\frac{\partial}{\partial x} q(x) \tilde{C}=0$. 
We may use the technique in section 5.2 to solve this equation. The solution to the above equation at $x_{0}$. $\tau_{0}$ is then used as the initial condition for the dittusion problem, where we now detine

$\eta=\frac{x-x_{0}}{\sqrt{\tau-\tau_{0}}}$.

We have thus produced a "global" solution.

For constant chemistry, velocity. and dispersion even simpler solutions are available. Lester et al. (1976). There are also methods available to produce threedimensional, analytical expressions for the $t$ lux at the seabed-sea interface with the velocity in the vertical direction.

Unfortunately. to produce really meaningtul bounds, the multicomponent chemistry must be used. At this writing. this chemistry is not available.

One further point should be noted betore leaving this section, namely, a nonchemistry lower bound on the time required for an ion to reach an intertace can be computed. To calculate this bound. the energy and mass transport equations are solved neglecting the chemistry. and assuming the ion being transported is of trace type. 
i.e.. has no effect on the fluid density. These equations can be solved using the current state-ot-the-art numerical PDE techniques.

\subsection{Numerical Considerations}

In this section we will attempt to give an overview of the numerical difficulties expected in trying to solve the governing PDEs. As mentioned in the introduction, a detailed account can be found in Treadway (1981). In the sections on simplified models. several different types of structure arose in the solutions. namely. stiftness. "dittusional singularness." and shocks.

Any of the three can result in numerical ditficulties, which individually can, at times, be handled, but collectively will overtax the current state-of-the-art techniques for numerically solving PDEs. Shock problems are "routinely" solved in hydrodynamics, however, the shocks are generally quite smeared. On the other hand. "diffusional singularness." i.e.. when the diffusion coefficient essentially goes to zero, is not routinely handled even for ordinary differential equations (ODE's). Because the diffusion coefficient changes so rapidly, it is very easy to produce negative concentrations which can in turn lead to a negative diffusion coefticient. Consequently, the problem becomes mathematically unstable, i.e.. the solution becomes unbounded with time. To overcome the problem, either 
the concentration must be clipped so that it remains positive or a large amount of "artificial damping" must be added. In either case. the resulting solution need not resemble the true solution.

When the multicomponent problem is considered, more difficulties arise. Some will be similar to the ditticulties previously mentioned; however, some new difticulties must be considered. For example, consider the simplest multicomponent chemistry

$\bar{c}_{i}=k_{d}^{i} c_{i}$

where $K_{d}^{i}$ is a constant. For radionuclides. $k_{d}^{i}$ may vary by many orders of magnitude between the various species. As a result. the ions are effectively transported at difterent rates. In order to accurately track the ions. each component must have its own dynamically generated spacial mesh. There is currently much research being directed at producing dynamic meshes. However. to date there are no automatic, multicomponent generation techniques available, even in one dimension. When multidimensionality is added to the foregoing discussion. trying to numerically solve the governing PDEs is a very tormidable problem indeed. However, as mentioned previously, many ditticulties disappear when the radionuclides are present in low concentration amounts. 


\subsection{Conclusions}

From a consideration of the mathematical model, it is evident that much work must be done in experimentally determining the functional coefficients. especially, with regard to the chemistry. Even if thermal effects are neglected, which is reasonable some distance from the cannister. the chemistry is necessary not only to determine bounds. but also to develop the necessary numerical techniques.

The mathematical model also pointed out the need to consider "electrokinetic" coupling for the seabed Project because of the charged. clay-like composition of the medium, particularly for nigh concentrations.

The simplified models presented snowed that several numerical difficulties could arise. These problems were due to stiffness. "diffusional singularness." "shocks," multiple components, and multidimensionality. At this time, a numerical simulation for high concentrations or multiple components would be extremely difficult and probably would not be very believable.

Consequently, it is the author's opinion that with the availability of multicomponent chemistry, the best course would be to use simplified models to develop bounds for the concentrations and fluxes. 
Intentiona $11 y$ Left Blank 
APPENDIX

To numerically solve Equation (5.9) subject to BCs (5.10), repeated here tor completeness.

$$
\frac{d^{2} \tilde{c}}{d \tilde{\eta}^{2}}+\frac{\eta \tilde{w}}{2}(c) \frac{d \tilde{c}}{d \eta}=0
$$

BC

$$
\tilde{C}(0)=1 \text {, and } \underset{L}{\lim } \underset{L}{\tilde{C}(L)}=0
$$

we write (A.1) as a system, viz..

put

$$
\begin{aligned}
& y_{1}=\tilde{C} \\
& y_{2}=\frac{d \tilde{C}}{d \eta}
\end{aligned}
$$

then

$$
\begin{aligned}
& y_{1}^{\prime}=y_{2} \\
& y_{2}^{\prime}=-\frac{\eta \tilde{w}}{2}(c) y_{2}
\end{aligned}
$$

where

$$
c=c_{0} Y_{1}
$$


Furthermore.

$$
y_{1}(0)=1 \text { and } \lim _{L \rightarrow \infty} y_{1}(L)=0 \text {. }
$$

If we knew how to approximate the second condition in (A.5) we 11 , we could use simple shooting to solve (A.4). (A.5), i.e.. adjust $y_{2}(0)$ until the above condition is satisfied with $y_{1}(0)=1$ being the initial condition. Unfortunately, how we chose to make this approximation had a significant effect on the answer at low concentrations.

On the other hand. we know that for $c \leq 10^{-11}$, $\tilde{w}$ is constant. $w_{\star}$. Consequently tor $y_{1} \leq 10^{-11} / C_{0}(A .4)$ becomes

$$
\begin{aligned}
& y_{1}^{\prime}=y_{2} \\
& y_{2}^{\prime}=-\frac{\eta}{2} w_{*} y_{2}
\end{aligned}
$$

It we impose the BCs

$$
y_{I}\left(\eta_{\star}\right)=\tilde{C}_{\star} \text { and } \lim _{L \rightarrow \infty} y_{1}(L)=0
$$

where $\eta_{*}$ is, for the moment, arbitrary and solve (A.6) we tind

$$
y_{\perp}(\eta)=\tilde{c}(\eta)=\frac{\tilde{c}_{\star} \operatorname{erfc}\left(\frac{\eta}{2} \sqrt{w_{\star}}\right)}{\operatorname{erfc}\left(\frac{n_{\star}}{2} \sqrt{w_{\star}}\right)} \text {. }
$$


Differentiating (A.8) wrt $\eta$ and evaluating at $\eta_{\star}$, we obtain

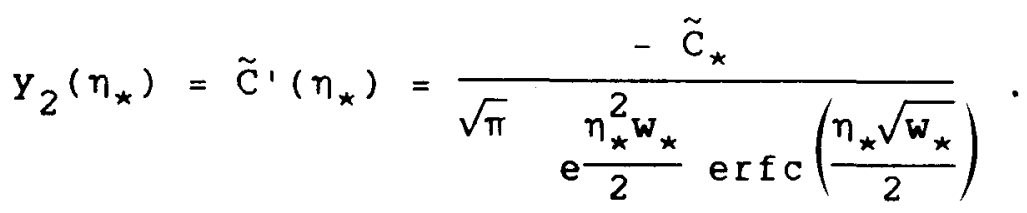

(A.8) and (A.9) represent the asymptotic behavior of (A.4) for low (trace) concentrations. If $\eta_{\star}$ were known, then Equation (A.4) could be integrated backwards to $\eta=0$.

To find $n_{\star}$ we use the BCs

$$
y_{1}(0)=1 \text { and } y_{I}(L)=10^{-8}
$$

and solve (A.4) by simple shooting. Figure $3 a$. (Other approximations could have been used.) The initial approximation to $\eta_{*}$ is obtained from the intersection of the flat portion and curved portion of the curve in Figure $3 a$. We then adjust $\eta_{\star}$ in (A.9) and solve (A.4) subject to BC

$$
y_{1}\left(\eta_{\star}\right)=\tilde{c}_{\star} \text { and } y_{2}\left(\eta_{\star}\right)=C^{\prime}\left(\eta_{\star}\right)
$$

until

$$
y_{1}(0)=1
$$

Since for the parameters consider in the report $\frac{\eta_{\star}}{2} \sqrt{w_{\star}}$ is very $l a r g e$. the denominator in (A.9) must be evaluated using an asymptotic expansion. Abramowitz and stegan, (1965). 
The SLATEC library code SNSQE, was used to solve the nonlinear problems associated with the second condition in (A.10) and (A.12). In the forward shooting problem. the code DEBDF was used because of stiffness problems, while in the backward problem. DERKF was used. The stiffness problem was due to (A.10) in that the step size being used was being restricted by the integration method, not by accuracy. 
1. Abramowitz, M. and I. A. Stegun, editors, Handbook of Mathematical Functions. Dover Publications, New York, Chapter 7 (1965).

2. Bear, J.. Dynamics of Fluids in Porous Media. American Elsevier. New York (1972).

3. Bolt, G. H., and P. H. Groenevelt, "Coupling Phenomena as a Possible Cause of "Non-Darcian" Behavior of Water in soil." Bulletin of the International Association of scientific Hydrology, XIV, \#2, pp 17-26 (1969).

4. Bradley, W. G.. and N. H. Sweed, "Rate Controlled constant Pattern Fixed-Bed Sorption with Axial Dispersion and Nonlinear Multicomponent Equilibria." A.I.Ch.E symposium Series 7l. \#152. Pp 59-78 (1975).

5. Cooper. H. H. Jr.. "The Equation of Groundwater Flow in Fixed and Deforming Coordinates." J. of Geophys. Res.. 71. \#20. pp 4785-4790 (1966).

6. Crank, J., Mathematics of Diffusion, University Press, Oxford (1956).

7. de Groot. S. R.. Thermodynamics of Irreversible Processes. North-Holland Publ. Co.. Amsterdam (1951).

8. Elrick, D. E., P. H. Groenevelt, and T. J. M. Blom, "Problems of Chemical Reactions and Biological processes in soils" in Heat and Mass Transfer in the Biosphere, ed. by D. A. de Vries and N. H. Afgan, chapter 37, pp 537-548, Scripta Book Co.. washington, D.C. (1975).

9. Erickson, K. L.. Private Communication (1977).

10. Freeze. A.. "Three-Dimensional. Transient, Saturated-Unsaturated Flow in a Groundwater Basin." water Resources Research, 1, \#2. pp 347-364 (1971).

11. Groenevelt, P. H. and G. H. Bolt, "Non-Equilibrium Thermodynamics of the soil-water system," J. of Hydrology, 1, pp 358-388 (1969).

12. Helfferich, F. and G. Klein, Multicomponent Chromatography. Marcel Dekker. New York (1970).

13. Hickox, C. E. Jr.. "Steady Thermal Convection at Low Rayleigh Number from Concentrated sources in Porous Media." SAND77-1529. Sandia Laboratories. Albuquerque, NM (1977). 
14. Hilbert, D. and Courant, R. Methods ot Mathematical Physics. Vol. II. Interscience Publ.. New York (1966).

15. Katchalsky, A, and P. F. Curran, Non-Equilibrium Thermodynamics in Biophysics. Harvard University Press. Cambridge (1965).

16. Lester. D. H., G. Jansen, and H. C. Burknolder, "Migration of Radionuclide Chains Through Absorbing Medium." BNWL-SA-5079, Battelle Pacific Northwest Laboratories, Richland. WA (1976).

17. Mercer. J. W.. and C. R. Faust. "Geothermal Reservoir simulation: 1. Mathematical Models for Liquid-and Vapor-Dominated Hydrothermal Systems." Water Resources Research. 15. \#1. PP 23-30 (1979).

18. Millero, F. J.. "Seawater as a Multicomponent Electrolyte." PP 3-80. in The sea. Vo1. 5, Marine Chemistry ed. by E. D. Goldberg. Wiley, New York (1974).

19. Nuttul1, H. E.. Memorandum of Record, January 5. 1976. Sandia Laboratories, A $\perp$ buquerque, NM.

20. Oleinik. O. A. "Uniqueness and stability of the Generalized Solution of the Cauchy Problem for a Quasi-linear Equation," Amer. Math. Soc. Transt. Series 2, Vol 33, pp 285-290 (1963).

21. Roache, P. J. Computational Fluid Dynamics, 2nd Edition. Hermosa Publishers. Albuquerque (1976).

22. Rastogi. R. P., K. Singh, and M. L. Srivasteva. "CrossPhenomenological Coefticients. XI. Nonlinear Transport Equations." J. ot Phys. Ch.. 73. \#l. PP 46-51 (1969).

23. Schimme1. W. P. JI., C. E. Hickox Jr., J. C. Dunn, and W. D. Sandberg. "Heat Transter/Thermal Physics in the Deep Ocean Sediments." in Seabed Disposal Program Annual Report. January to December 1977. Vol. II-Appendices, edited by D. M. Talbert, SAND78-1359. Sandia Laboratories. Albuquerque, NM (1978).

24. Taylor, S. A., and J. W. Cary. "Linear Equations tor the Simultaneous Flow of Matter and Energy in a Continuous soil system," Soil science society of America, Proceedings, 28. pp 167-172, 1964 .

25. Treadway. A. H.. "Comparison of Numerical Techniques tor the Solution of the Equations Governing Radionuclide Ion Migration in Porous Media." SAND81-0846. Sandia Laboratories. Albuquerque. NM (1981), unpublished manuscript. 


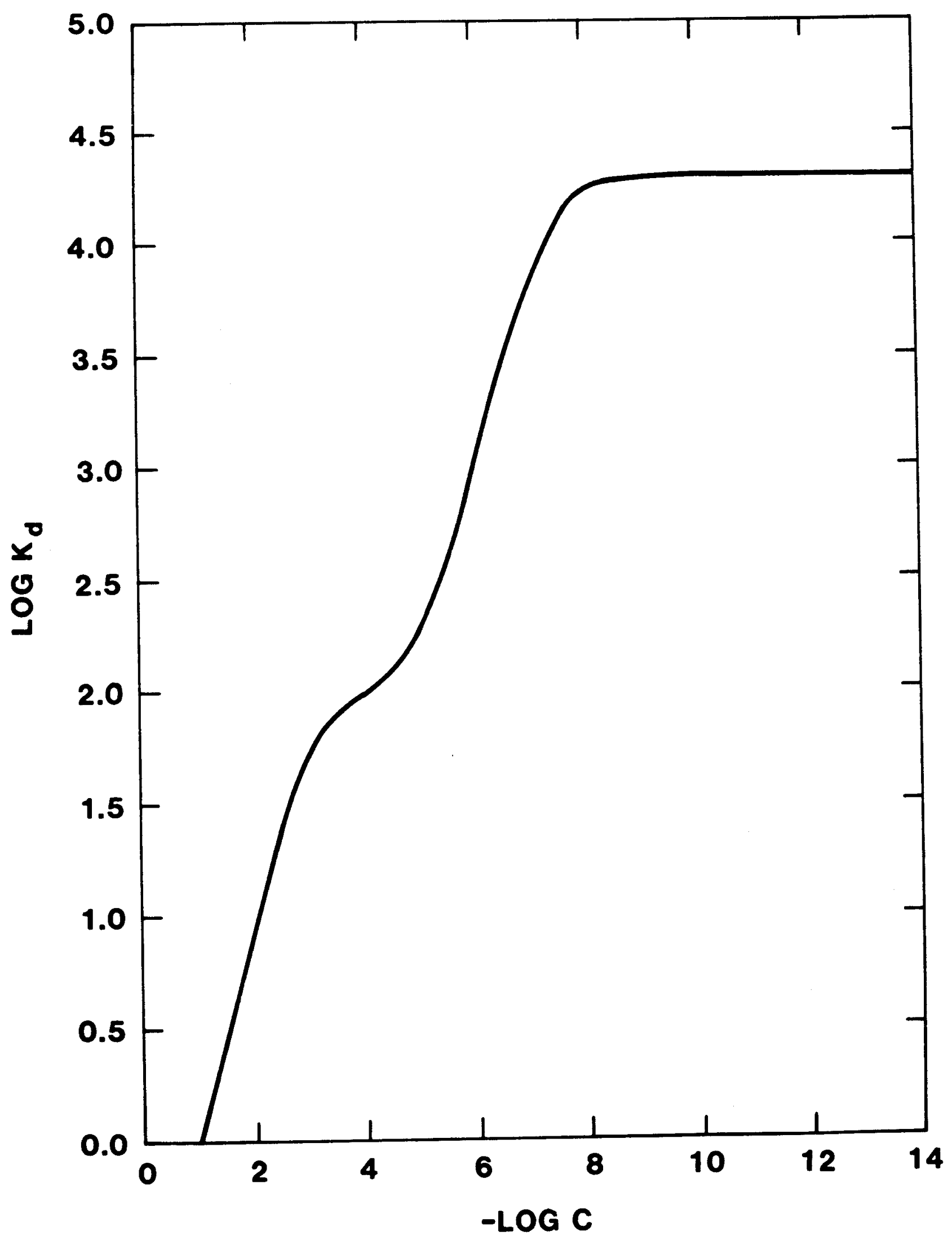

Figure 1. Experimental Distribution Coefficient versus Liquid Concentration 


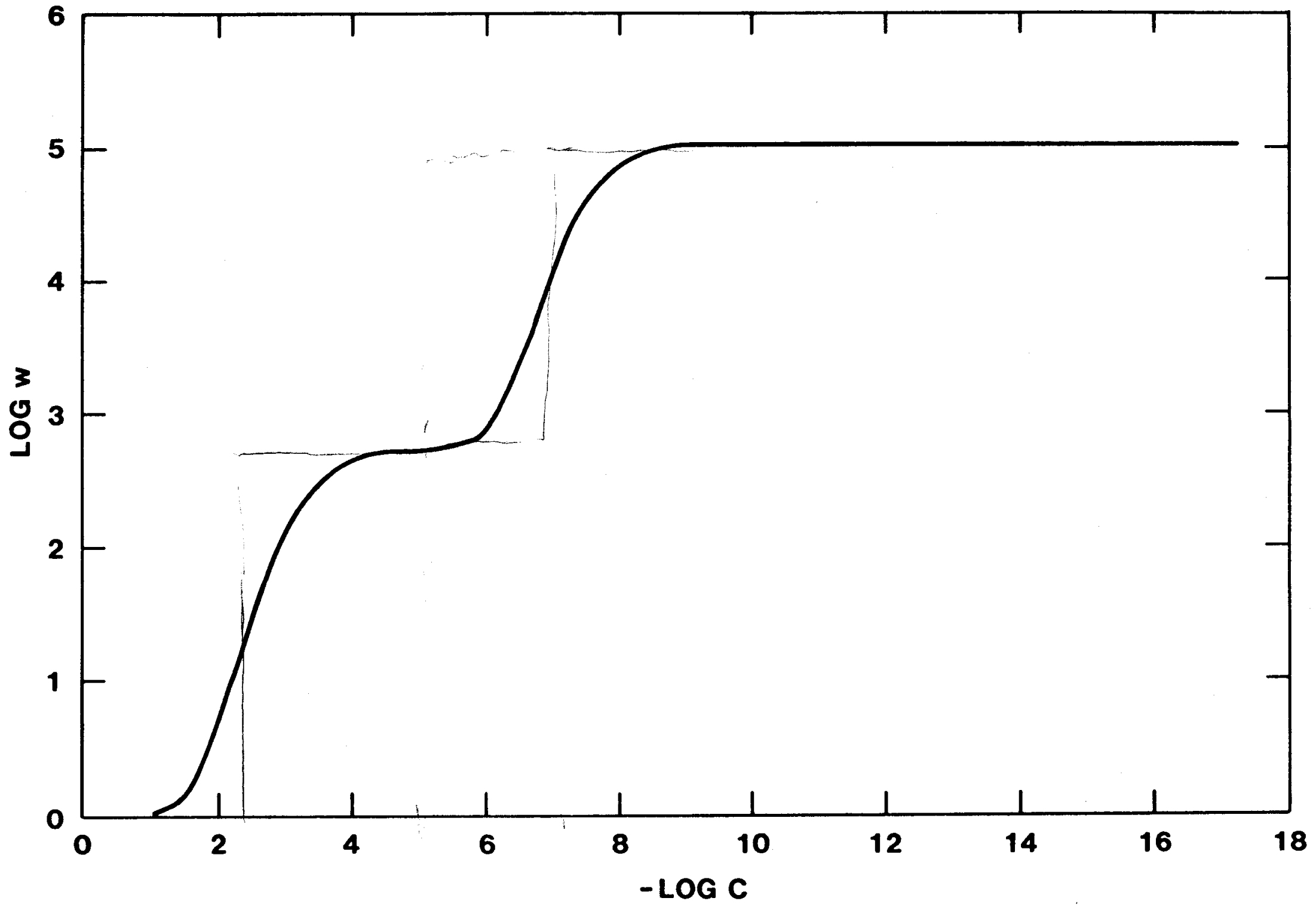

Figure 2. Derivative of Total Concentration versus Liquid Concentration 


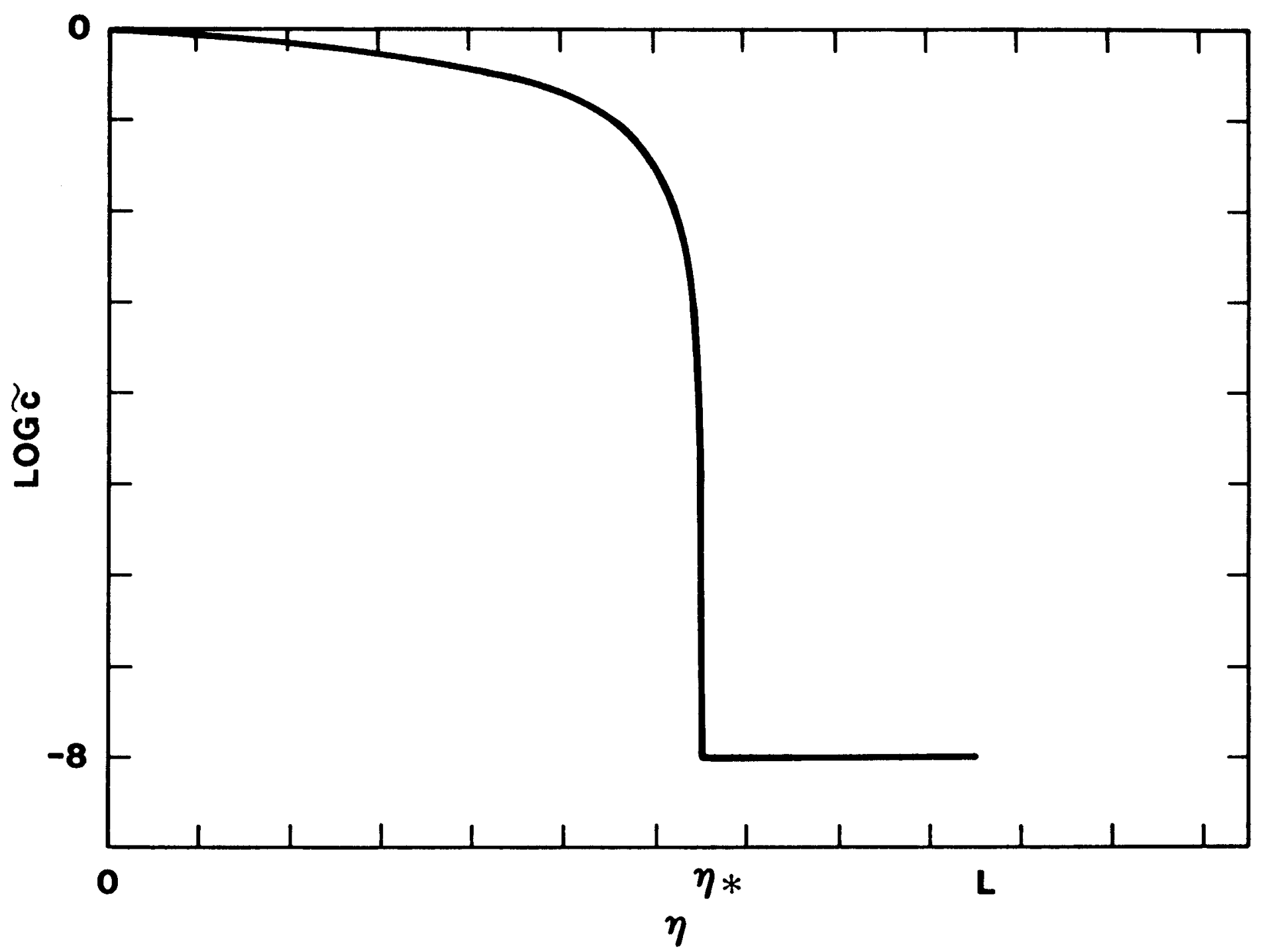

Figure 3a. A Numerical Solution Resulting from Forward shooting 


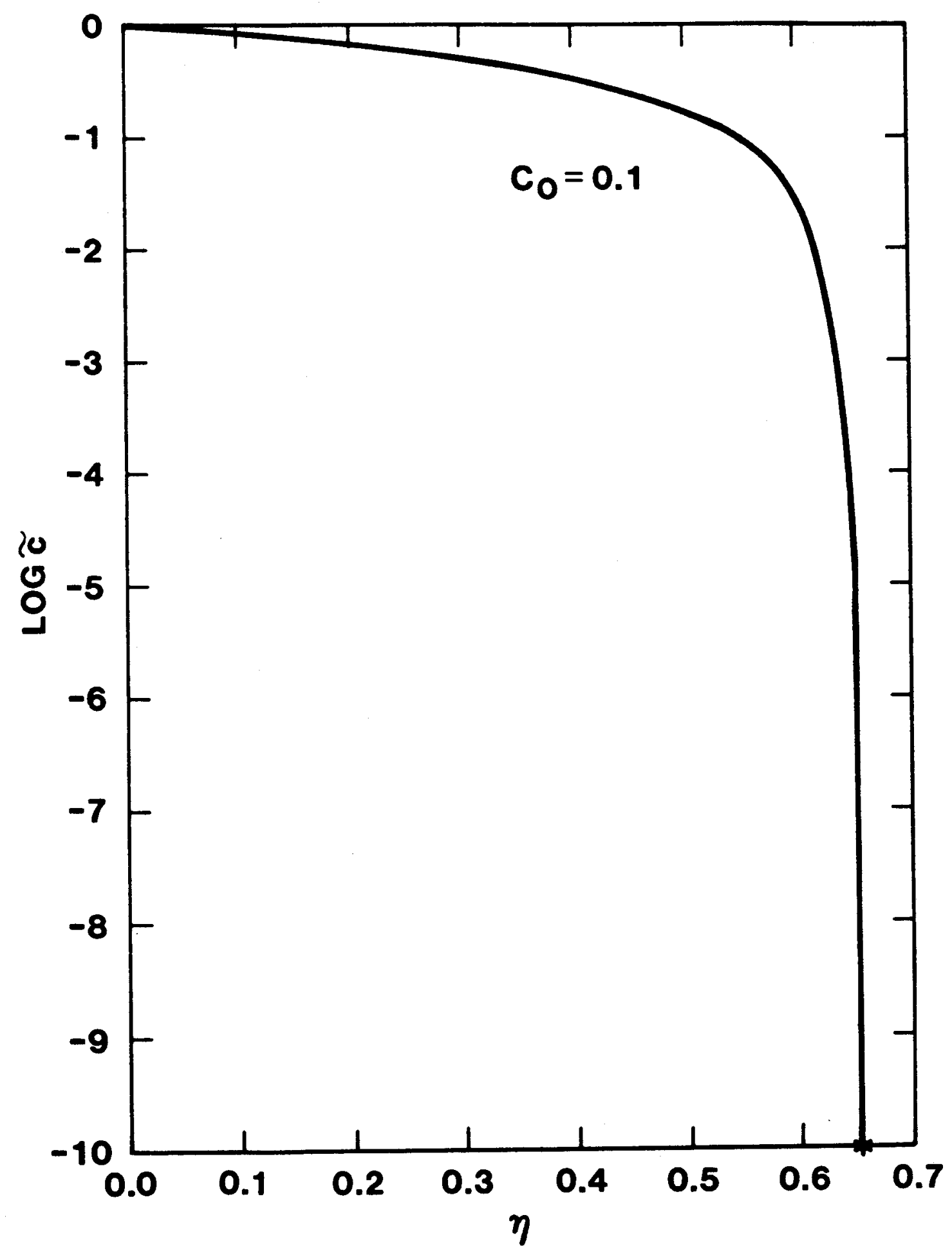

Figure 3b. Numerical solution for an Initial Concentration of . I 


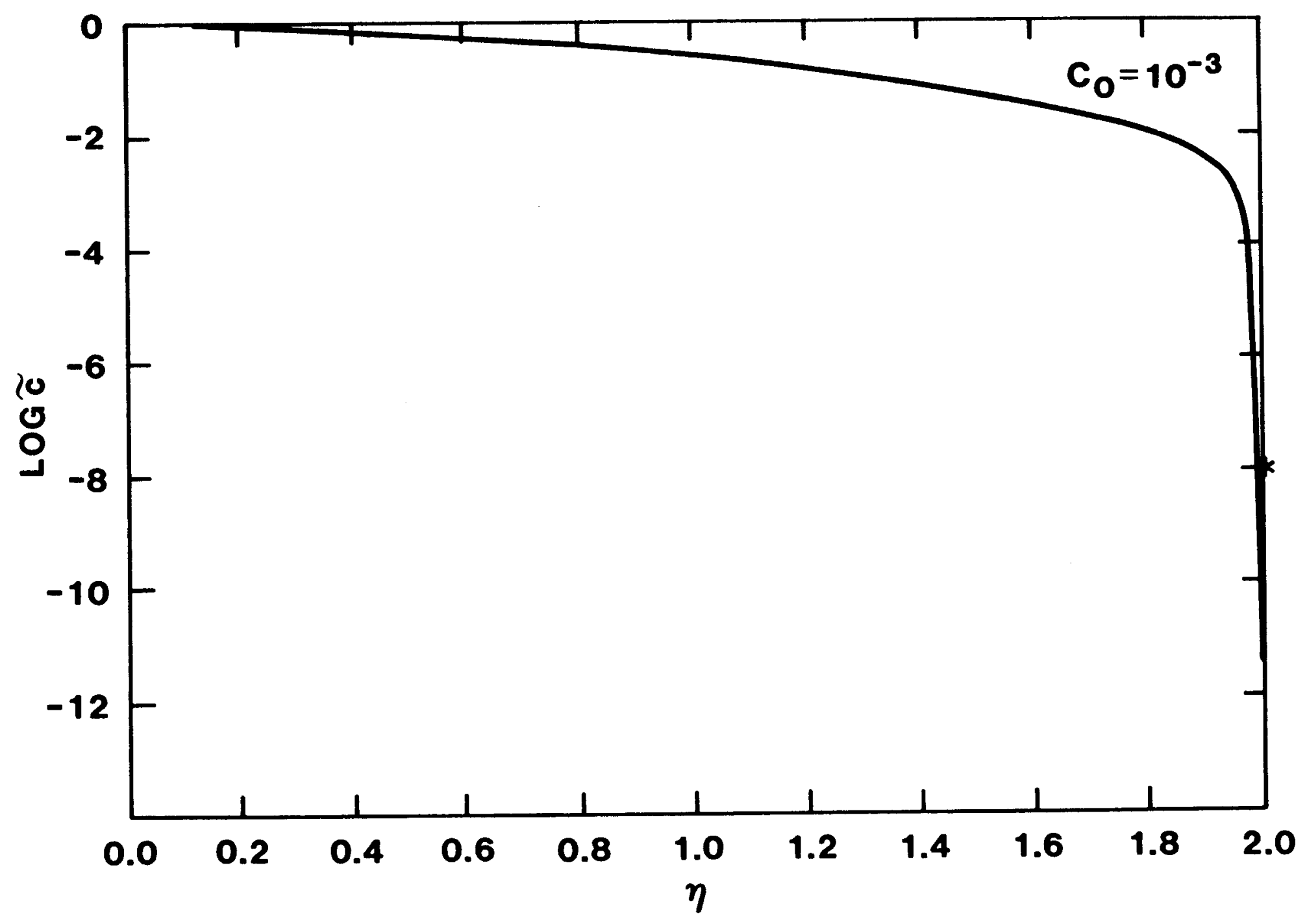

Figure 3c. Numerical solution for an Initial Concentration of $10^{-3}$ 
U

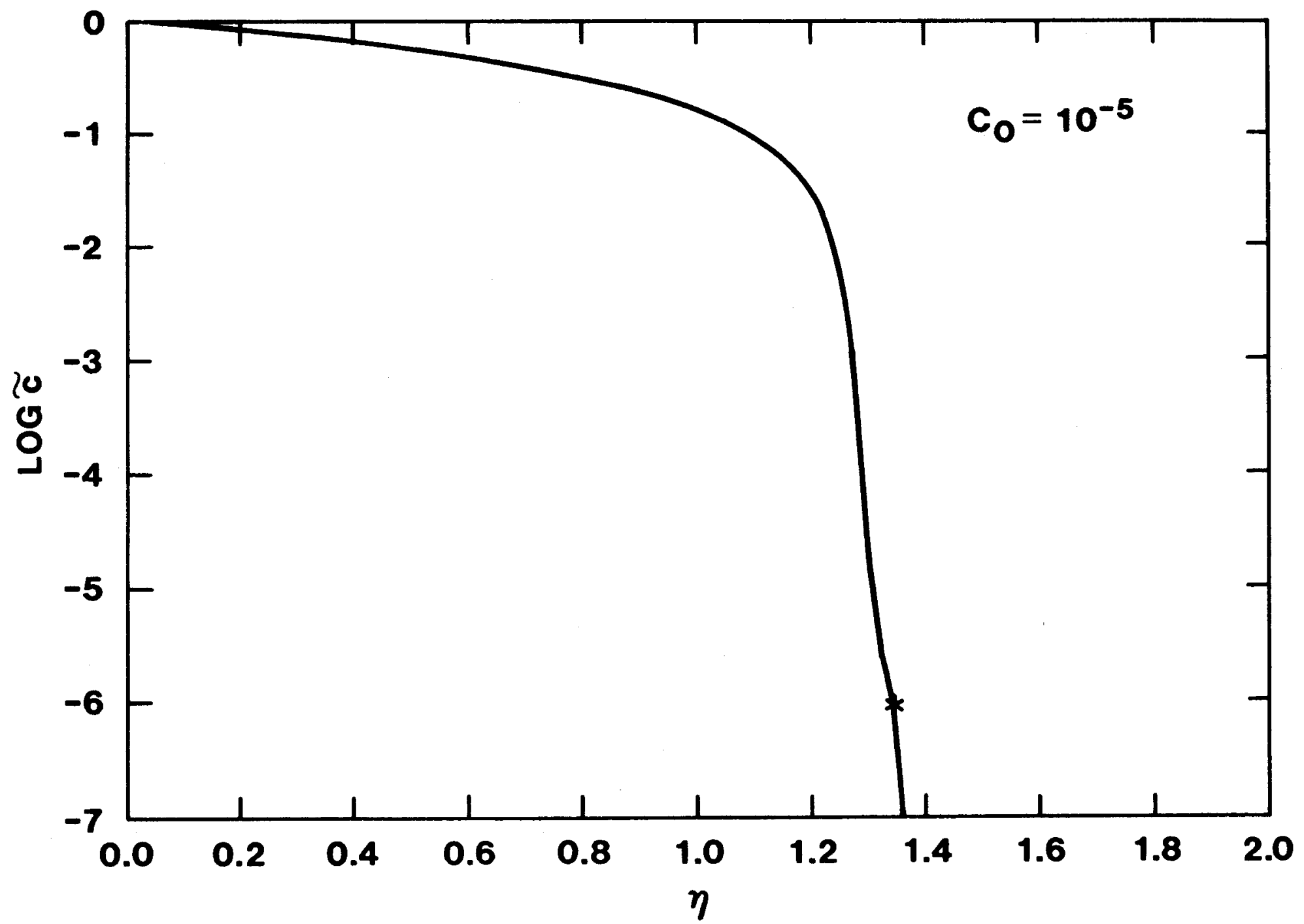

Figure 3d. Numerical solution for an Initial Concentration of $10^{-5}$ 


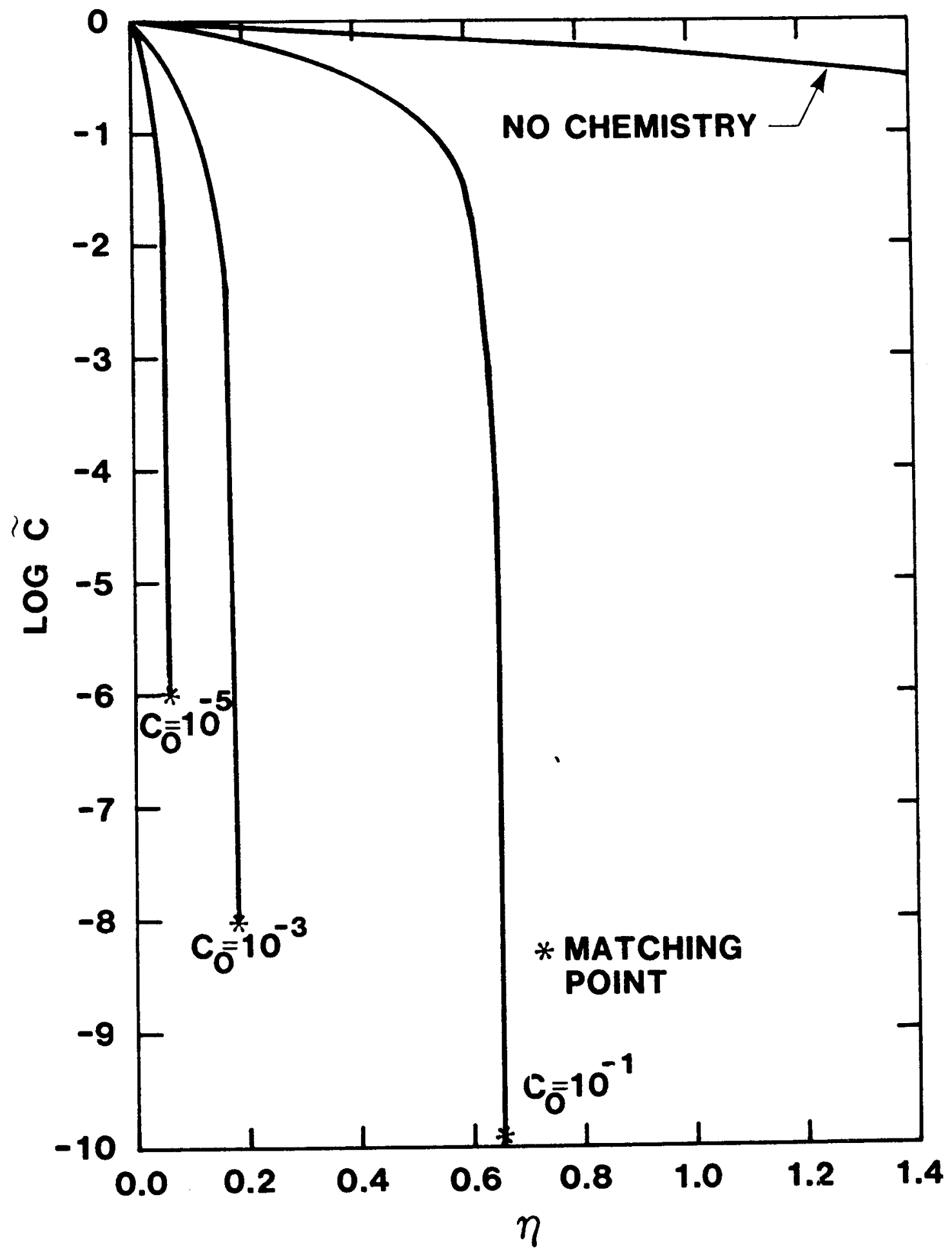

Figure 3e. The Effects of Initial Concentration and Chemistry 


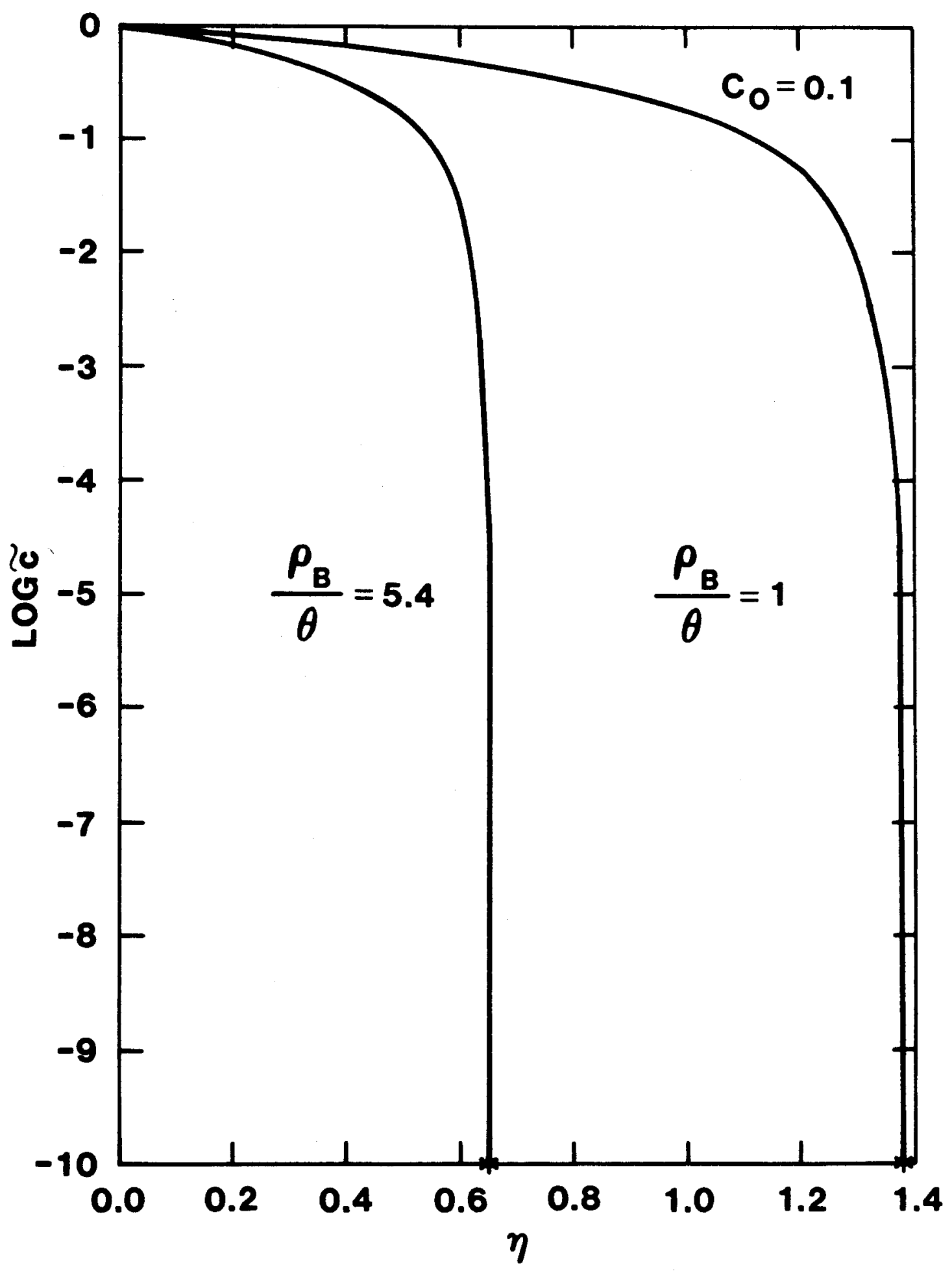

Figure 3f. The Effects of Soil Properties 


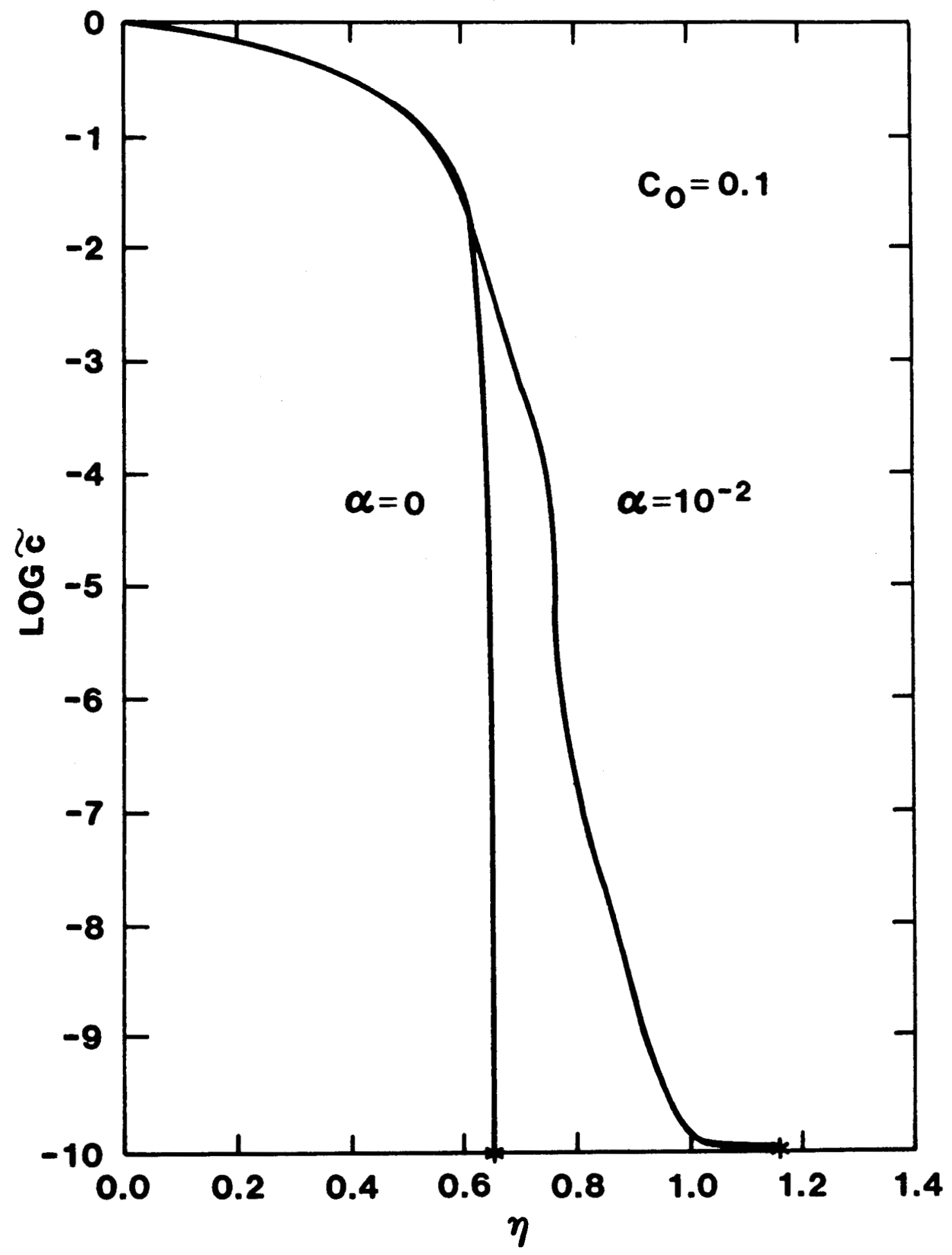

Figure 4. Combined Liquid and Solid Diffusion 

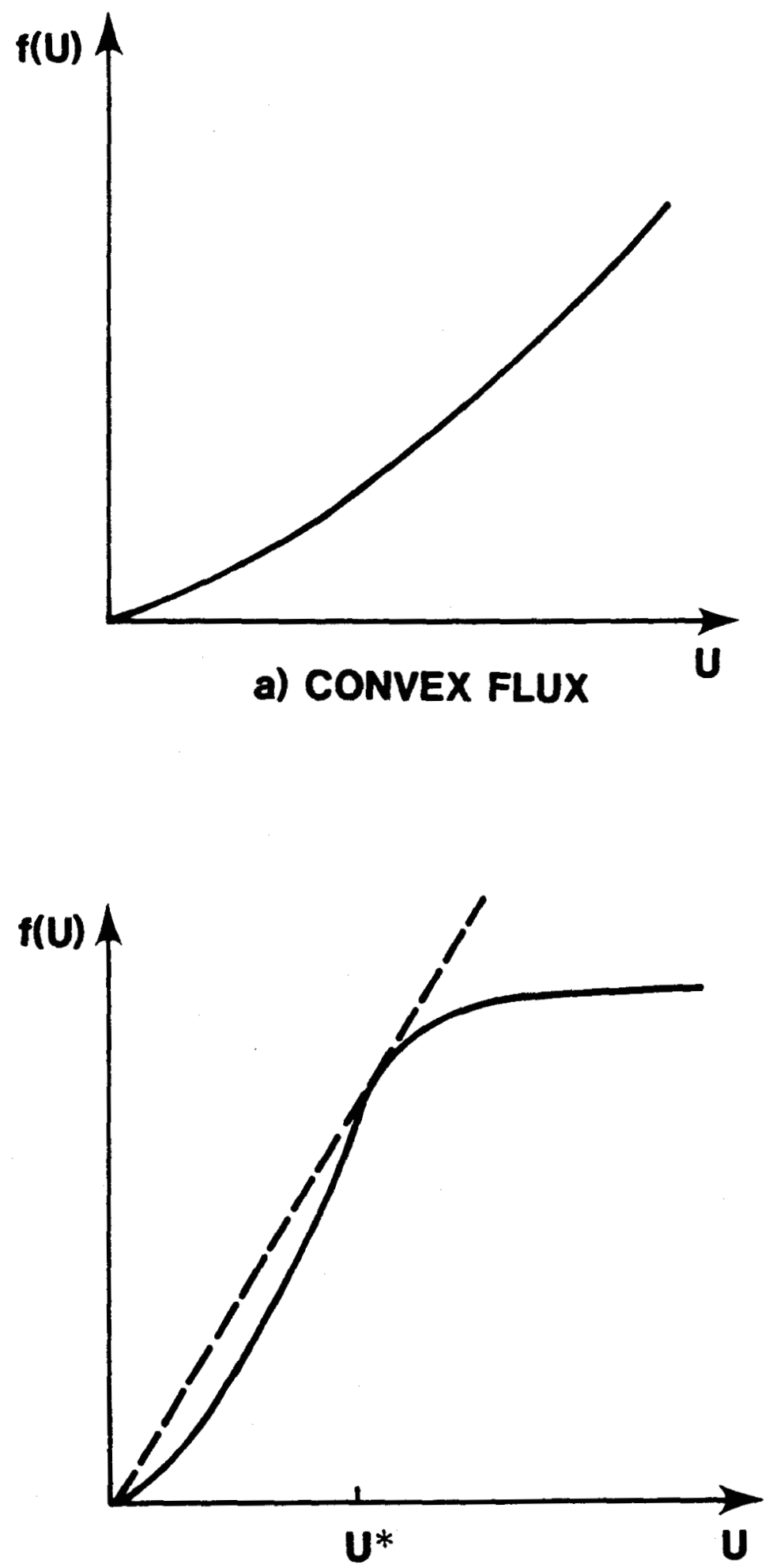

b) NONCONVEX FLUX

Figure 5. Examples of Fluxes 


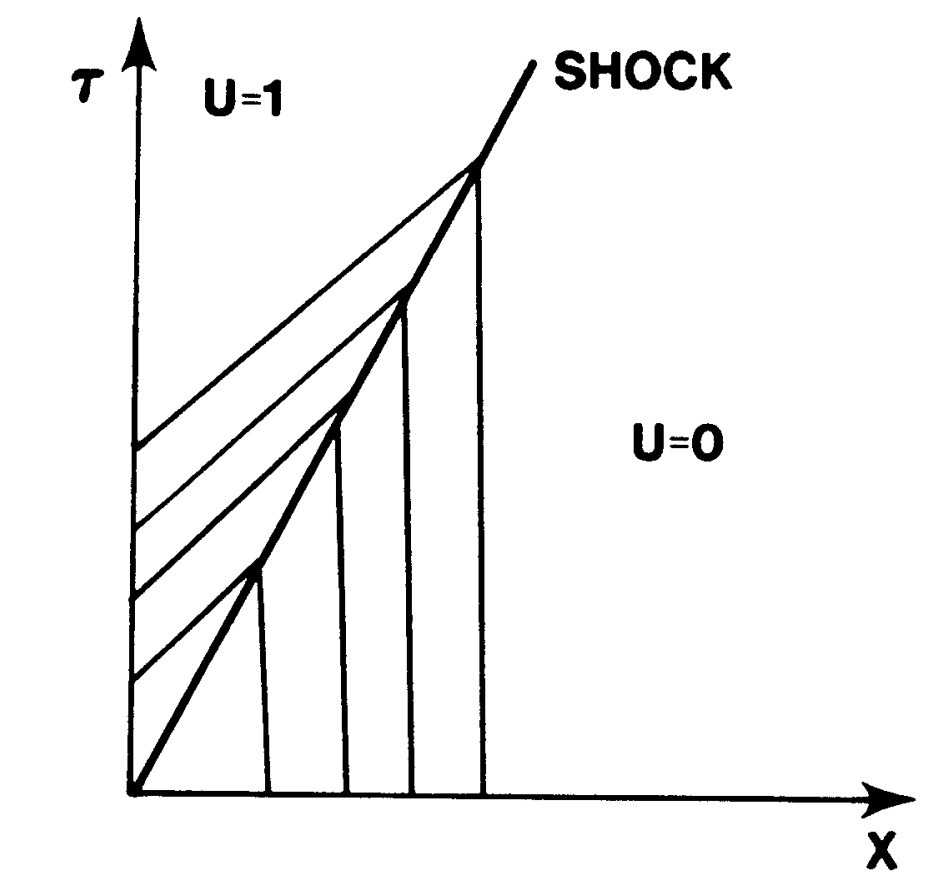

a) SHOCK SOLUTION FOR CONVEX FLUX

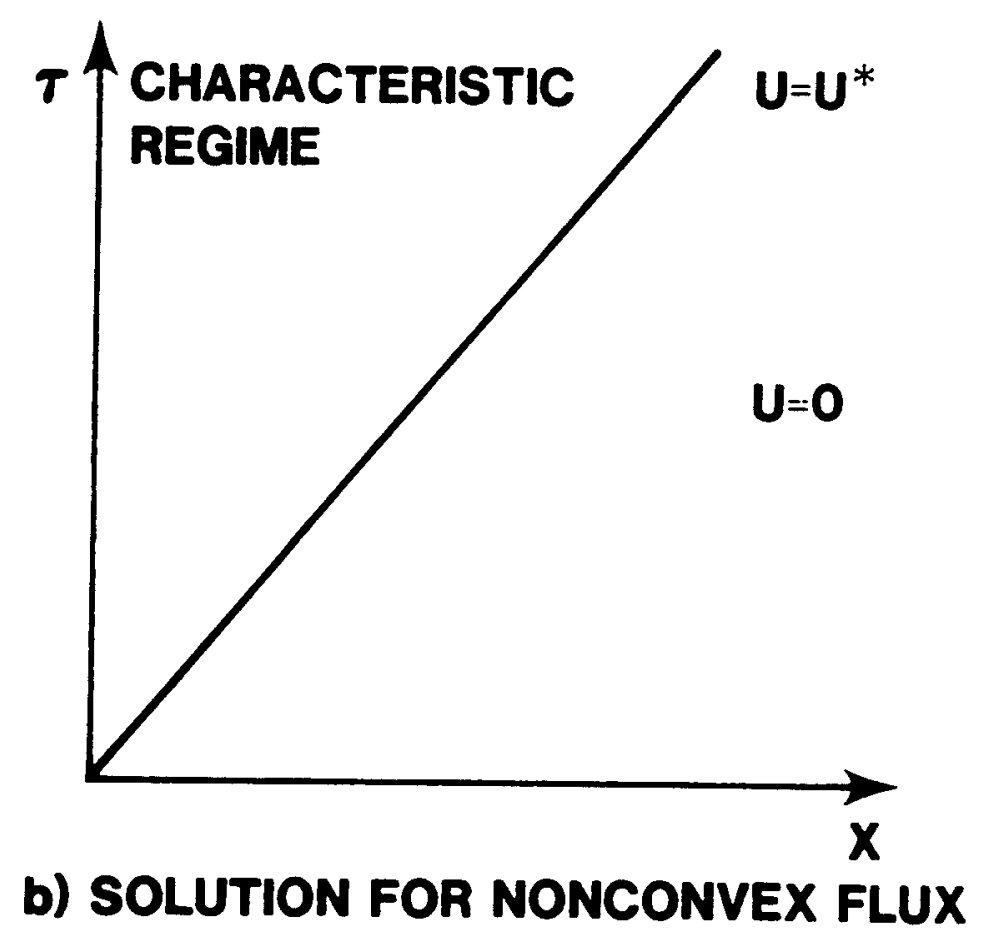

Figure 6. The Effect of Flux Shapes on $X-\tau$ Diagrams 


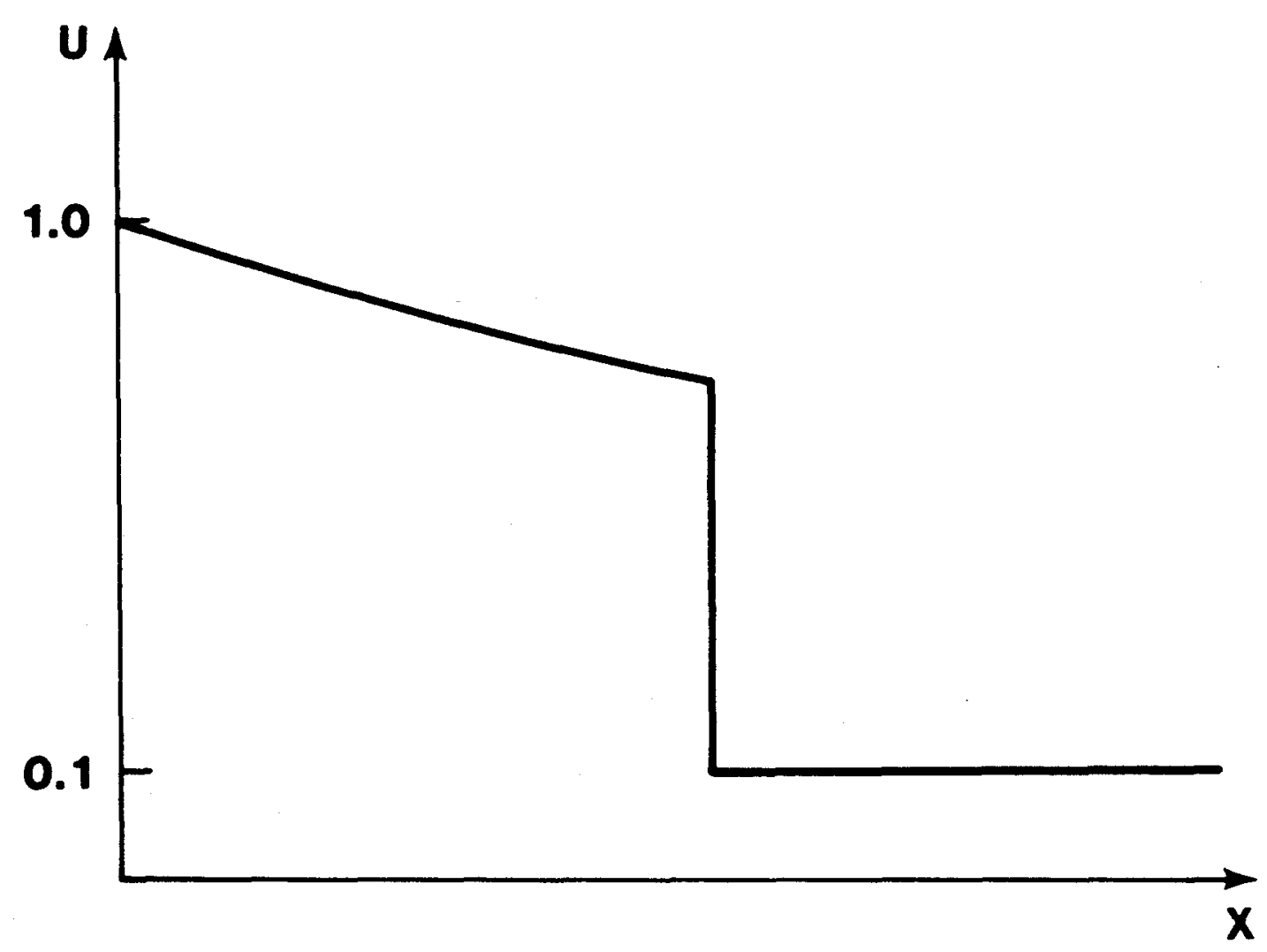

Figure 7. Example of a solution for a Nonconvex Flux

60 


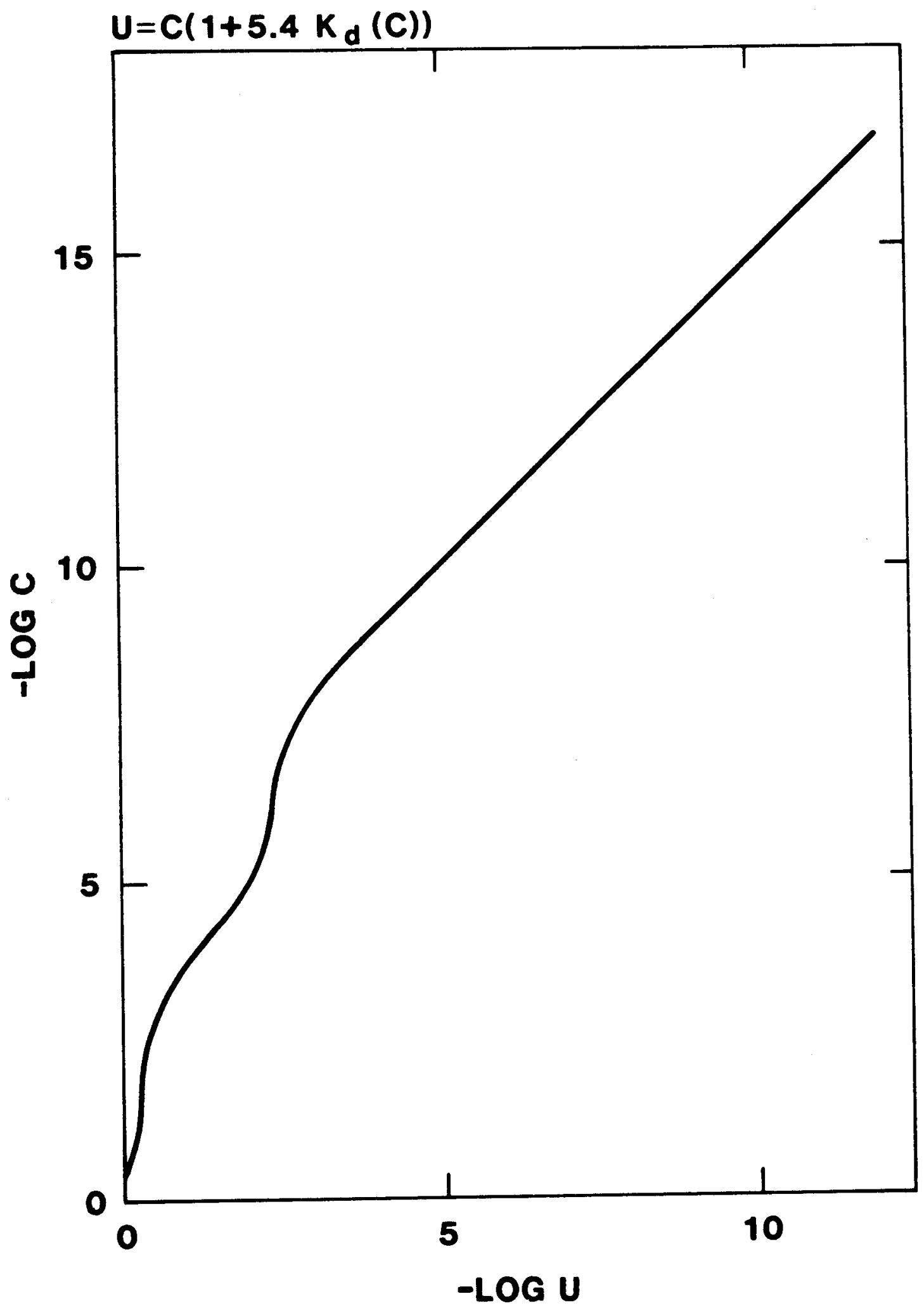

Figure 8. Liquid Concentration versus Total Concentration 


\section{LATE TIME/DIFFUSION DOMINATED REGIME}

\section{TRANSITION REGIME}

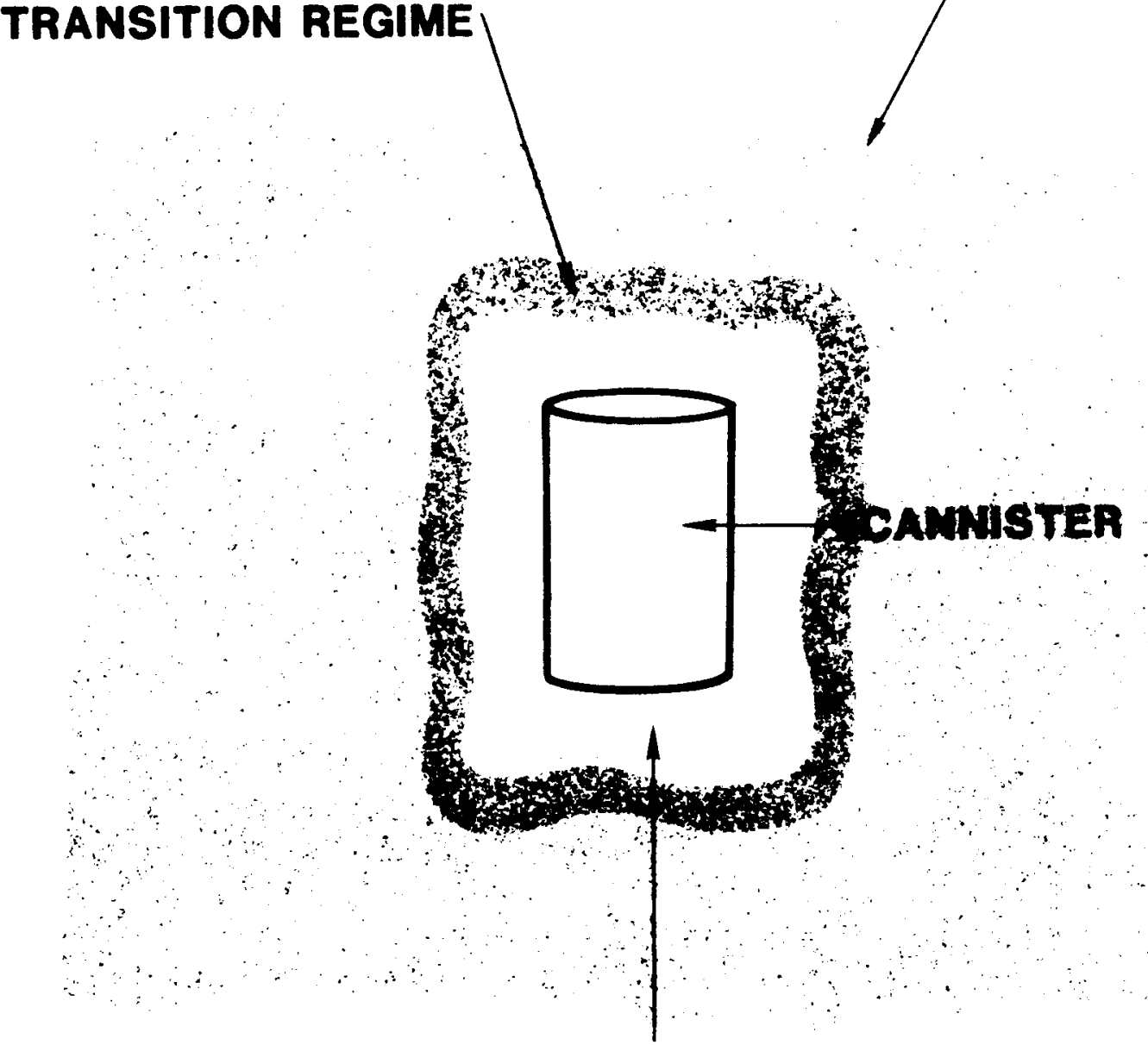

EARLY TIME/ADVECTION DOMINATED REGIME

Figure 9. Flow Regimes 


\section{DISTRIBUTION :}

Centre d'Information Geologique Ecole des Mines de Paris

Attn: G. de Marsily

35 Rue St. Honore

77305 Fontainbleau

France

Whiteshell Nuclear Research Establishment

Attn: D. M. Wuschke

Pinawa, Manitoba ROE ILO

Canada

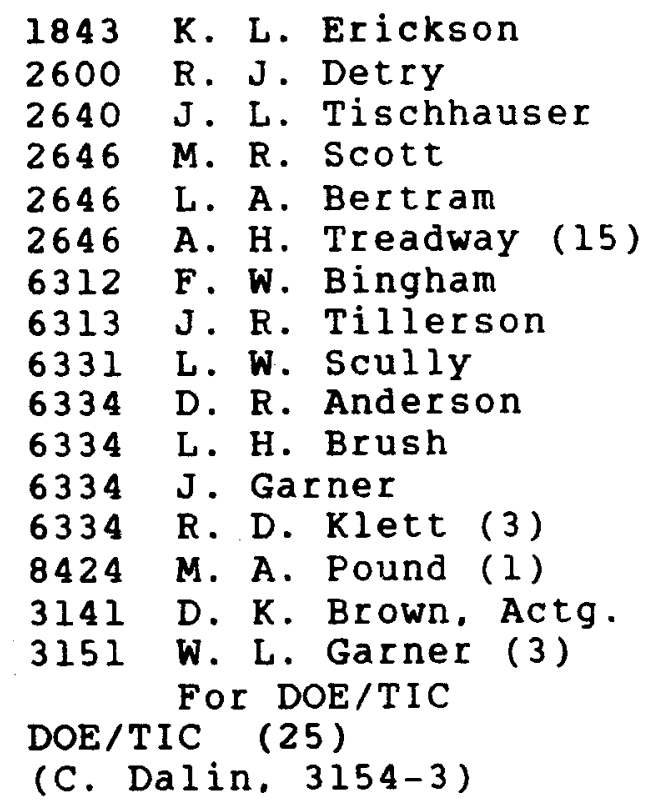

